\title{
Reduced expression of aquaporins in human intestinal mucosa in early stage inflammatory bowel disease
}

This article was published in the following Dove Press journal:

Clinical and Experimental Gastroenterology

9 January 2015

Number of times this article has been viewed

\section{Petr Ricanek ${ }^{1,2}$ \\ Lisa K Lunde ${ }^{3}$ \\ Stephan A Frye' \\ Mari Støen' \\ Ståle Nygård ${ }^{4}$ \\ Jens P Morth ${ }^{5,6}$ \\ Andreas Rydning ${ }^{2}$ \\ Morten H Vatn ${ }^{7,8}$ \\ Mahmood Amiry- \\ Moghaddam ${ }^{3}$ \\ Tone Tønjum ${ }^{1,9}$}

'Department of Microbiology, Oslo University Hospital, Rikshospitalet, Oslo, ${ }^{2}$ Department of Gastroenterology, Akershus University Hospital, Lørenskog and Campus Ahus, Institute of Clinical Medicine, University of Oslo, Lørenskog, ${ }^{3}$ Department of Anatomy, Institute of Basic Medical Sciences, University of Oslo, ${ }^{4}$ Bioinformatics Core Facility, Institute for Medical Informatics, Oslo University Hospital and University of Oslo, ${ }^{5}$ Centre for Molecular Medicine, Nordic EMBL Partnership, University of Oslo, ${ }^{6}$ Institute for Experimental Research, Oslo University Hospital (Ullevaal), Oslo, ${ }^{7}$ EpiGen Institute, Campus Ahus, Institute of Clinical Medicine, University of Oslo, Lørenskog, ${ }^{8}$ Section of Gastroenterology, Oslo University Hospital, Rikshospitalet, Oslo, ${ }^{9}$ Department of Microbiology, University of Oslo, Oslo, Norway
Correspondence: Petr Ricanek Department of Gastroenterology, Akershus University Hospital, Sykehusveien 25, I478 Lørenskog, Norway

Tel +47 67960000

Fax +47 67962185

Email petr.ricanek@medisin.uio.no
Objectives: The aim of this study was to investigate the relationship between aquaporin (AQP) water channel expression and the pathological features of early untreated inflammatory bowel disease (IBD) in humans.

Methods: Patients suspected to have IBD on the basis of predefined symptoms, including abdominal pain, diarrhea, and/or blood in stool for more than 10 days, were examined at the local hospital. Colonoscopy with biopsies was performed and blood samples were taken. Patients who did not meet the diagnostic criteria for IBD and who displayed no evidence of infection or other pathology in the gut were included as symptomatic non-IBD controls. AQP1, 3, 4, 5, 7, 8, and 9 messenger RNA (mRNA) levels were quantified in biopsies from the distal ileum and colon by quantitative real-time polymerase chain reaction. Protein expression of selected AQPs was assessed by confocal microscopy. Through multiple alignments of the deduced amino acid sequences, the putative three-dimensional structures of AQP1, 3,7 , and 8 were modeled.

Results: AQP1, 3, 7, and 8 mRNAs were detected in all parts of the intestinal mucosa. Notably, AQP1 and AQP3 mRNA levels were reduced in the ileum of patients with Crohn's disease, and AQP7 and AQP8 mRNA levels were reduced in the ileum and the colon of patients with ulcerative colitis. Immunofluorescence confocal microscopy showed localization of AQP3, 7, and 8 at the mucosal epithelium, whereas the expression of AQP1 was mainly confined to the endothelial cells and erythrocytes. The reduction in the level of AQP3, 7, and 8 mRNA was confirmed by immunofluorescence, which also indicated a reduction of apical immunolabeling for AQP8 in the colonic surface epithelium and crypts of the IBD samples. This could indicate loss of epithelial polarity in IBD, leading to disrupted barrier function.

Conclusion: AQPs 1 and 8 and the aquaglyceroporins AQPs 3 and 7 are the AQPs predominantly expressed in the lower intestinal tract of humans. Their expression is significantly reduced in patients with IBD, and they are differentially expressed in specific bowel segments in patients with Crohn's disease and ulcerative colitis. The data present a link between gut inflammation and water/solute homeostasis, suggesting that AQPs may play a significant role in IBD pathophysiology.

Keywords: inflammatory bowel disease, Crohn's disease, ulcerative colitis, aquaporins, aquaglyceroporins

\section{Introduction}

Inflammatory bowel disease (IBD) is a chronic, relapsing disease of the gastrointestinal (GI) tract, with frequent onset during adolescence or early adulthood. IBD is characterized by chronic activation of the immune system with inflammation of the intestinal tract and leakage of fluid, solutes, and lipids in the bowel mucosa. Patients present with one of 
two clinical entities, namely Crohn's disease (CD) or ulcerative colitis (UC). CD is a transmural disease that is often localized to one or more segments of the small and large bowels, but can affect all parts of the intestine. UC is a mucosal disease that affects the large bowel and occasionally the distal part of the ileum. ${ }^{1}$ Chronic diarrhea, as well as the social discomfort associated with it, is a major symptom in both CD and UC.

Water and solutes move across the single layer of intestinal epithelial cells in a transcellular or paracellular manner. In IBD patients, chronic diarrhea can be caused by impaired ion transport and dysfunctional tight junctions, leading to a "leaky" intestinal epithelium; this "leakiness" may be a primary or secondary mechanism underlying the etiology of IBD. High levels of circulating tumor necrosis factor- $\alpha$ (TNF- $\alpha$ ) and several other cytokines can increase intestinal permeability and cause edema. ${ }^{2}$

Aquaporins (AQPs) are a family of pore-forming proteins that efficiently and selectively transport water and/or other small uncharged solutes across biological membranes. ${ }^{3,4}$ AQPs belong to a distinct family of membrane-transport proteins that are selective for water molecules, and water levels are regulated across the hydrophobic plasma membrane. Studies of AQPs have provided important insight into mechanisms that mediate water homeostasis in human health and disease. ${ }^{5}$ Based on comparative genomics, 13 AQPs (AQP0-AQP12) have been characterized to date. The AQP superfamily has been divided into three subgroups: AQPs 0, 1, 2, 4, 5, 6, and 8; aquaglyceroporins (AQPs 3, 7, 9, 10); ${ }^{5}$ and the largely uncharacterized subgroup, which includes AQPs 11 and 12. ${ }^{6}$ All AQPs are permeable to water, but AQP6 has been reported to function not only as a water channel but also as an anion channel with halide permeability when treated with $\mathrm{Hg}^{2+}$. 7 AQP3 and AQP8 also allow transport of hydrogen peroxide $\left(\mathrm{H}_{2} \mathrm{O}_{2}\right)^{8-10}$ and show a preference for ammonia over water while excluding the ammonium cation $(\mathrm{NH} 4+) .{ }^{11} \mathrm{AQP} 8$ is phylogenetically different from all other human AQP isoforms, possessing a unique constriction region resulting in its substrate specificity. ${ }^{12}$ The aquaglyceroporins 3,7 , and 10 exhibit permeability to both water and glycerol, while aquaglyceroporin 9, in addition to water, transports glycerol and small solutes, such as urea. ${ }^{13}$ The aquaglyceroporins contain two additional peptide spans required for the transport of glycerol, urea, and even larger solutes. ${ }^{14,15}$ AQP6 and AQP8 are localized to intracellular membranes, while all other AQPs facilitate transport across the plasma membrane. ${ }^{16} \mathrm{AQPs} 11$ and 12 share common motifs in the primary structure that are unique to the AQP superfamily; however, they have not been shown to be permeable to water or other solutes ${ }^{13,17-19}$ and their function is not fully understood.
AQPs are widely expressed in many human tissues and cell types, including secretory and absorptive epithelial cells. ${ }^{4}$ Recent studies suggest that several AQPs could play (previously unanticipated) physiological or pathophysiological roles. ${ }^{20}$ AQPs 1, 3, 4, 5, 7, 8, and 9 are expressed in the human GI tract and associated tissues. ${ }^{21,22}$ The broad distribution of AQPs in the human bowel suggests that they are likely to play an important role in channel-mediated water transport, intestinal permeability, and fluid secretion/absorption, and is consistent with a potential role for AQPs in the pathophysiology of the GI system. AQP3 and AQP8 expression has been found to be abnormal in human UC patients in remission. ${ }^{23}$ The potential role of AQPs in early IBD or other types of GI dysfunction in humans has not yet been investigated in a systematic manner.

In this work, we test the hypothesis that AQPs contribute to dysfunctional water and solute transport in individuals with untreated IBD. The tissue-specific messenger RNA (mRNA) levels from selected AQP genes were monitored by quantitative real-time polymerase chain reaction (qRT-PCR) in biopsy samples from the distal ileum and proximal and distal colon of patients with CD or UC. The tissue distribution of selected AQPs was also assessed by using confocal microscopy with immunofluorescence (IF). The mRNA levels of selected inflammatory markers were also quantified.

\section{Materials and methods Patients}

Patients were recruited from the prospective Inflammatory Bowel Disease South-Eastern Norway (IBSEN) II study (2005-2007) investigating the genetic, immunologic, and environmental factors that contribute to IBD etiology. Patients suspected to have IBD on the basis of predefined symptoms, including abdominal pain, diarrhea, and/or blood in stool for more than 10 days, were examined at the local hospital. Colonoscopy with biopsies was performed, and blood samples were taken. Patients who did not meet the diagnostic criteria for $\mathrm{IBD}^{24}$ and who displayed no evidence of infection or other pathology in the gut were included as symptomatic non-IBD controls. Forty-three newly diagnosed patients and controls from the IBSEN II study ${ }^{25}$ were included in this cross-sectional study. Twenty-two of the patients had CD, ten had UC, and eleven were non-IBD controls, as described in Table 1. Four CD patients had ileitis, eight had colitis, and ten had ileocolitis (L1, L2, and L3, respectively, according to the Montreal classification) ${ }^{24}$ All ten UC patients had pancolitis. The eleven non-IBD patients were randomly chosen as symptomatic controls with normal endoscopic and histologic findings, five with diarrhea at inclusion and the others with different symptoms 
Table I Characterization of the study subjects

\begin{tabular}{|c|c|c|c|}
\hline & CD & UC & $\begin{array}{l}\text { Non-IBD } \\
\text { controls }\end{array}$ \\
\hline $\mathrm{n}$ & 22 & 10 & 11 \\
\hline Male, n (\%) & $10(45)$ & $8(80)$ & $6(55)$ \\
\hline \multirow[t]{2}{*}{ Age median (range) } & 30.7 & 30.2 & 32.1 \\
\hline & $(19.2-52.5)$ & $(|8|-6 \mid .0)$. & $(20.7-4 I . I)$ \\
\hline \multicolumn{4}{|l|}{ Distribution } \\
\hline lleitis, n (\%) & $4(18)$ & 0 & 0 \\
\hline Colitis, n (\%) & $8(36)$ & $10(100)$ & 0 \\
\hline Ileocolitis, n (\%) & $10(45)$ & 0 & 0 \\
\hline \multicolumn{4}{|l|}{ Symptoms } \\
\hline Abdominal pain, n (\%) & $12(55)$ & $5(50)$ & $7(64)$ \\
\hline Diarrhea, n (\%) & $15(68)$ & $9(90)$ & $5(45)$ \\
\hline Blood in stool, n (\%) & $5(23)$ & $9(90)$ & $3(27)$ \\
\hline Fever, n (\%) & I (5) & $2(20)$ & 0 \\
\hline Smoking, n (\%) & $7(32)$ & $\mathrm{I}(\mathrm{II})^{\mathrm{a}}$ & $3(27)$ \\
\hline CRP mg/L, median (range) & $26(5-108)$ & $24(7-94)$ & $7(7-7)^{\mathrm{b}}$ \\
\hline Fecal calprotectin, & 118 & 740 & $4.5(I-28)$ \\
\hline mg/kg, median (range) & $(I-6,59 I)$ & $(190-10,825)$ & \\
\hline $\begin{array}{l}\text { Clinical activity index } \\
\text { median (range) }\end{array}$ & $4.5(I-29)^{c}$ & $5(3-14)^{d}$ & \\
\hline
\end{tabular}

Notes: ${ }^{2}$ One missing value. 'bower cutoff value $7 \mathrm{mg} / \mathrm{L}$. 'Harvey-Bradshaw index. dSimple Clinical Colitis Activity Index.

Abbreviations: CD, Crohn's disease; UC, ulcerative colitis; IBD, inflammatory bowel disease; CRP, C-reactive protein.

that had led to inclusion in the study, as, for instance, abdominal pain, and/or blood in stool. Table 2 describes the clinical and endoscopic indices as well as $\mathrm{C}$-reactive protein and fecal calprotectin values in detail for each patient.

\section{Clinical specimens and processing of bowel biopsies}

Two doses of sodium phosphate (Phosphoral ${ }^{\circledR}$; Casen-Fleet, Madrid, Spain) were used for bowel cleansing. Colonoscopy was performed and mucosal biopsies were retrieved from the terminal ileum and the ascending and descending colon. The biopsies were taken from inflamed mucosal regions with biopsy forceps and immediately snap-frozen in liquid nitrogen or fixed in $4 \%$ formaldehyde. Inflammation was ubiquitous in UC patients, who presented with pancolitis, while the intestinal tract in $\mathrm{CD}$ patients was characterized by patchy inflamed regions.

\section{Three-dimensional homology modeling}

To model human AQP1, 3, and 7, Protein Data Bank (PDB) ID entry $1 \mathrm{~J} 4 \mathrm{~N}$ (bovine AQP1) ${ }^{26}$ was used as template, and to model AQP8, PDB ID entry 3D9S (human AQP5) 27 was employed. Initial multiple alignments with 20-25 orthologous sequences of $\mathrm{AQP} 1,3,7$, and 8 from various species were assembled, and sequences with sequence identity $>90 \%$ were left out. The alignments were based on the template structures and used to model the AQPs in the comparative protein structure modeling program, MODELLER.$^{28}$ For each template, a total of 100 models were generated, and the one with the lowest discrete optimized protein energy score ${ }^{29}$ was used for further analysis. Water molecules in the channel region were kept during the modeling, and complete tetrameric models were generated to allow analysis of the biologically active unit.

\section{Gene expression analyses}

RNA extraction and qRT-PCR of total RNA

The biopsies were homogenized using the MagNA Lyser instrument and MagNa Lyser Green Beads tubes (Roche Applied Science, Mannheim, Germany). Total RNA was extracted from $10 \mathrm{mg}$ of human fresh-frozen intestinal biopsies using the MagNA Pure LC RNA Isolation Kit III (Tissue) and the MagNA Pure LC instrument (Roche), and eluted into RNAse-free water. To generate complementary DNA (cDNA), $2 \mu \mathrm{g}$ total RNA was subjected to reverse transcriptase-PCR.

\section{qRT-PCR for mRNA levels in gut tissue}

qRT-PCR was performed by target amplification, using cDNA as template, TaqMan Gene Expression Master Mix (Applied Biosystems, Foster City, CA, USA), and the Taqman Gene Expression Assays Kit (Applied Biosystems). The sequences of the primers employed are listed in Table S1. Transcripts of the genes encoding AQP1, 3, 4, 5, 7, 8, and 9 were assessed, as they were expected to be expressed in the gut. ${ }^{30}$ All values were normalized to an endogenous control (reference gene), human glyceraldehyde 3-phosphate dehydrogenase (GAPDH), 6-carboxyfluorescein (FAM)/minor groove binder(MGB) Probe; Thermo Fisher Scientific, Waltham, MA, USA), to account for variability in the concentration and quality of the total RNA and in the conversion efficiency of the reverse transcription reaction. A number of housekeeping genes were tested as the endogenous control, and all gave similar values as GAPDH. Three replicates of a $20-\mu \mathrm{L}$ qRT-PCR reaction (TaqMan ${ }^{\circledR}$ Gene Expression Master Mix Protocol; Applied Biosystems) were performed. A 7900HT Real-Time PCR System (Applied Biosystems) and standard-mode thermal cycling conditions were used: $50^{\circ} \mathrm{C}$ for 2 minutes (holding stage, required for optimal uracil-N glycosylase [UNG] activity), $95^{\circ} \mathrm{C}$ for 10 minutes (holding stage), then 40 cycles with $95^{\circ} \mathrm{C}$ for 15 seconds, and $60^{\circ} \mathrm{C}$ for 1 minute.

\section{qRT-PCR data analysis}

For qRT-PCR data analysis, the comparative $\mathrm{C}_{\mathrm{T}}$ method was employed (the $\Delta \Delta \mathrm{C}_{\mathrm{T}}$ method). ${ }^{31}$ This method makes 
Table 2 Disease location, clinical and endoscopic activity indices, CRP, and fecal calprotectin values for patients with Crohn's disease and those with ucerative colitis

\begin{tabular}{|c|c|c|c|c|c|c|c|}
\hline Patient ID & Location & $\begin{array}{l}\text { Age, } \\
\text { years }\end{array}$ & Sex & HBI & Modified $^{a}$ SES-CD ${ }^{56}$ & $\begin{array}{l}\text { CRP, } \\
\text { mg/L }\end{array}$ & $\begin{array}{l}\text { Fecal } \\
\text { calprotectin, } \\
\mathrm{mg} / \mathrm{kg}\end{array}$ \\
\hline \multicolumn{8}{|c|}{ Crohn's disease } \\
\hline 51 & LI & 22 & $\mathrm{~F}$ & 17 & 2 & 38 & 285 \\
\hline 31 & LI & 38 & $\mathrm{~F}$ & 5 & I & 7 & 29 \\
\hline 168 & LI & 39 & $\mathrm{~F}$ & I & 2 & 25 & 721 \\
\hline 204 & LI & 52 & M & 1 & 2 & 5 & - \\
\hline 53 & L2 & 27 & M & 29 & 2 & 43 & - \\
\hline 73 & L2 & 27 & $M$ & 6 & 2 & 7 & 45 \\
\hline 121 & L2 & 29 & $\mathrm{~F}$ & 3 & I & 12 & 52 \\
\hline 26 & L2 & 32 & M & 4 & 2 & 7 & 1 \\
\hline 37 & L2 & 35 & $\mathrm{~F}$ & 2 & 2 & 7 & 30 \\
\hline 81 & L2 & 37 & $\mathrm{~F}$ & 1 & 2 & 7 & 843 \\
\hline 9 & L2 & 44 & M & 8 & 1 & 7 & 32 \\
\hline 4 & L2 & 52 & M & 6 & 2 & 7 & 477 \\
\hline 1,034 & L3 & 19 & $\mathrm{~F}$ & 6 & 2 & 91 & - \\
\hline 165 & L3 & 20 & $\mathrm{~F}$ & 2 & 2 & 26 & 477 \\
\hline 94 & L3 & 21 & $\mathrm{~F}$ & 13 & 2 & 47 & 956 \\
\hline 107 & L3 & 22 & $\mathrm{~F}$ & 7 & 2 & 11 & 118 \\
\hline 194 & L3 & 26 & $M$ & 3 & I & 7 & - \\
\hline 146 & L3 & 27 & M & 10 & 2 & 108 & 6,591 \\
\hline 169 & L3 & 32 & $\mathrm{~F}$ & 4 & I & 11 & I \\
\hline 137 & L3 & 33 & M & 4 & I & 61 & 16 \\
\hline 36 & L3 & 39 & $\mathrm{~F}$ & 4 & I & 7 & - \\
\hline 49 & L3 & 39 & M & 9 & 2 & 21 & 354 \\
\hline Patient ID & Extension & Age & Sex & SCCAI & Mayo ${ }^{\mathrm{b}}$ score & CRP & Fecal calprotectin \\
\hline \multicolumn{8}{|c|}{ Ulcerative colitis } \\
\hline 86 & E3 & 18 & $M$ & 4 & 2 & 7 & 740 \\
\hline 1,008 & E3 & 19 & $M$ & 3 & 1 & 7 & - \\
\hline 59 & E3 & 20 & $M$ & 4 & 2 & 7 & 303 \\
\hline 84 & E3 & 20 & $M$ & 4 & 2 & 7 & 707 \\
\hline 19 & E3 & 28 & $\mathrm{~F}$ & 11 & 3 & 94 & 10,825 \\
\hline$|, 02|$ & E3 & 31 & $M$ & 14 & 3 & - & - \\
\hline 1,009 & E3 & 36 & $\mathrm{~F}$ & 3 & 2 & 7 & - \\
\hline 2,012 & E3 & 41 & $M$ & 6 & 2 & 13 & 7,221 \\
\hline 44 & E3 & 41 & $M$ & 7 & 3 & 7 & 190 \\
\hline 93 & E3 & 61 & $M$ & 11 & 2 & 68 & 3,878 \\
\hline
\end{tabular}

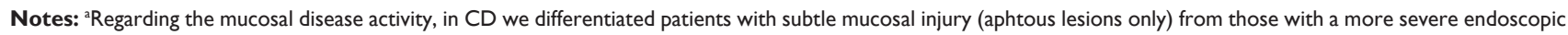
grade of inflammation (ulcers or more) using a modification of the SES-CD. This simple two-category index assessment was similar to a previous report from the IBSEN cohort. 'Partial endoscopic Mayo score. - indicates missing value.

Abbreviations: CD, Crohn's disease; HBI, Harvey-Bradshaw Index; ID, identification number; SCCAI, Simple Clinical Colitis Activity Index; F, female; M, male; SESCD, Simple Endoscopic Score for Crohn's Disease; CRP, C-reactive protein; L, location according to the Montreal classification; E, extension, according to the Montreal classification; IBSEN, Inflammatory Bowel Disease South-Eastern Norway.

use of the $\mathrm{C}_{\mathrm{T}}$ value, ie, the number of cycles at which the fluorescence exceeds the threshold, for the genes of interest, relative to the corresponding $\mathrm{C}_{\mathrm{T}}$ value for a control gene (GAPDH in our application). Gene expression was measured by the quantitation of cDNA relative to a calibrator sample (reference sample), which served as a physiological reference and was the cDNA from a nonIBD patient, although not one of the non-IBD patients included in the study. Results were thus normalized to an endogenous control (GAPDH) and the relative expression was obtained, thereby providing indirect information on target mRNA levels.

\section{Statistical analysis of qRT-PCR data}

Differences in gene expression between groups were assessed using one-sampled (ileum versus right colon versus left colon) and two-sampled (CD versus UC versus non-IBD) and (ileitis versus colitis versus ileocolitis in CD) $t$-tests on the 
$\Delta \Delta \mathrm{C}_{\mathrm{T}}$ values. For each comparison, multiple testing (testing ten genes at the same time) was corrected for by calculating Benjamini-Hochberg $q$-values. ${ }^{32}$ Tests with $q$-values $<10 \%$ were considered significant, corresponding to false discovery rates of $<10 \%$. Gene expression ratios between two groups $A$ and $B$ were calculated by using $2^{\left(\mathrm{m}_{\mathrm{B}}-\mathrm{m}_{\mathrm{A}}\right)}$, where $\mathrm{m}_{\mathrm{A}}$ and $\mathrm{m}_{\mathrm{B}}$ were the mean $\Delta \Delta \mathrm{C}_{\mathrm{T}}$ values for the two groups. The analyses were performed using the statistical programming language R. ${ }^{33}$

\section{Histological analysis}

\section{Tissue preparation}

Biopsies were immersion-fixed in 10\% formaldehyde phosphate-buffered saline solution (PBS), embedded in paraffin, and cut into $4-\mu \mathrm{m}$ sections on a Vibratome (VT1000S, Leica Microsystems, Wetzlar, Germany).

\section{Confocal microscopy and IF}

After washing and blocking with 2\% bovine serum albumin (BSA) in PBS, gut biopsy sections were incubated overnight with primary antibodies anti-AQP1 (1:1000, polyclonal antirabbit; Alpha Diagnostics, San Antonio, TX, USA), AQP3 (1:100, polyclonal anti-rabbit; Sigma-Aldrich Co., St Louis, MO, USA), anti-AQP4 (1:1000, polyclonal anti-rabbit, Chemicon Millipore, Temecula, CA, USA), anti-AQP5 (1:100, polyclonal anti-rabbit, Calbiochem, EMD Chemicals Inc., Darmstadt, Germany), anti-AQP7 (1:50, polyclonal anti-rabbit; Santa Cruz Biotechnology, Inc., Santa Cruz, CA, USA), anti-AQP8 (1:50, polyclonal anti-goat; Santa Cruz Biotechnology, Inc.), and anti-AQP9 (1:100, polyclonal anti-rabbit; Alpha Diagnostics). After washing, the gut biopsy sections were incubated with $\mathrm{Cy} 3$ donkey anti-rabbit or $\mathrm{Cy} 3$ donkey anti-goat secondary antibodies (Jackson ImmunoResearch Europe Ltd, Suffolk, UK) diluted in 2\% BSA 1:1,000 in PBS for 1 hour. After washing, the gut sections were mounted on glass and photographed in a Zeiss LSM510 confocal microscope (Oberkochen, Germany).

\section{Specificity controls}

For the positive controls, sections from human organs known to express each AQP were incubated along with the gut sections as shown in Figure S1, while for the negative controls, sections were incubated in the absence of the primary antibody.

\section{Ethical considerations}

All patients provided informed written consent to be involved in this study, and ethical approval of the protocol for the study was given by the Regional Ethics Committee (http:// www.etikkom.no/REK/regionSorOst, reference number S-04209).

\section{Results}

\section{Novel three-dimensional models reveal distinct $A Q P$ signatures}

AQP models based on the deduced amino acid sequences were generated to visualize the three-dimensional (3D) water channel entrance and facilitate future work. The models are structurally biased toward the selected template structure; however, they do allow an impression of the structural differences that must be present between the models of the different AQPs. The human AQP1 shares $>90 \%$ sequence identity with the bovine AQP1, and the model will thus resemble the actual human structure to a high degree. The sequence differences are mostly mapped to the loop regions, but for a few exceptions, they are present in the transmembrane region, as shown in Figures 1A-4A. The models for AQP3, 7, and 8 are highly conserved in the water channel region, while the remainder of the molecular landscape is divergent. The structural interaction between Arg195 and Phe56 in AQP1 is conserved in AQP1, 3, and 7, while in AQP8 the phenylalanine equivalent to Phe56 in AQP1 is replaced by histidine (His72), thus retaining the chemical moiety of an aromatic residue.

\section{AQPs I, 3, 7, and 8 are predominantly expressed in human intestinal mucosa}

AQP gene expression was quantified by qRT-PCR, as demonstrated in Figures 1B-4B and Tables 3, S2, and S3. mRNAs encoding AQPs 1, 3, 7, and 8 were consistently expressed at a moderate to high level (Table 3 ). In contrast, expression of AQPs 4, 5, and 9 was below the threshold for detection by qRT-PCR (Table S2). The remaining experiments therefore focused on expression of AQPs 1, 3, 7, and 8. A summary of the general trends in AQP expression detected by mRNA levels is provided in Table 4.

\section{Differential expression of AQPs in small and large bowel}

AQP1 and AQP3 mRNA levels were present in higher levels in the small bowel than in the large bowel, while the opposite was observed for AQP8, as presented in Table 3. AQP7 mRNA levels were higher in the left colon than those in the right colon in non-IBD controls, and higher in the ileum than in the right colon in $\mathrm{UC}$ patients. 
A

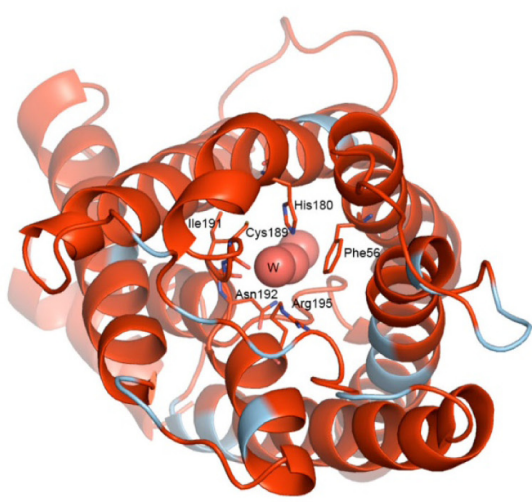

C

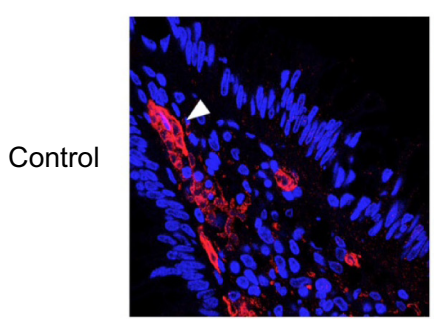

CD
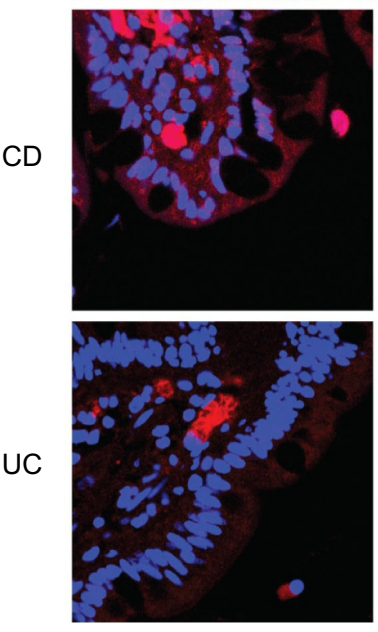

B

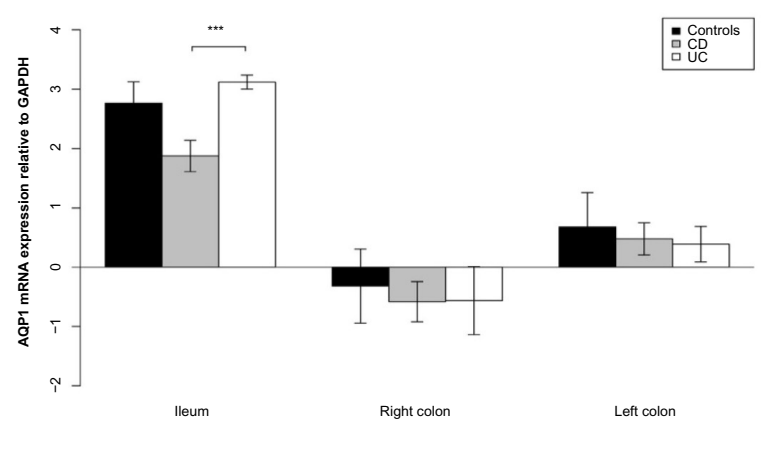

Colon surface

Colon crypt
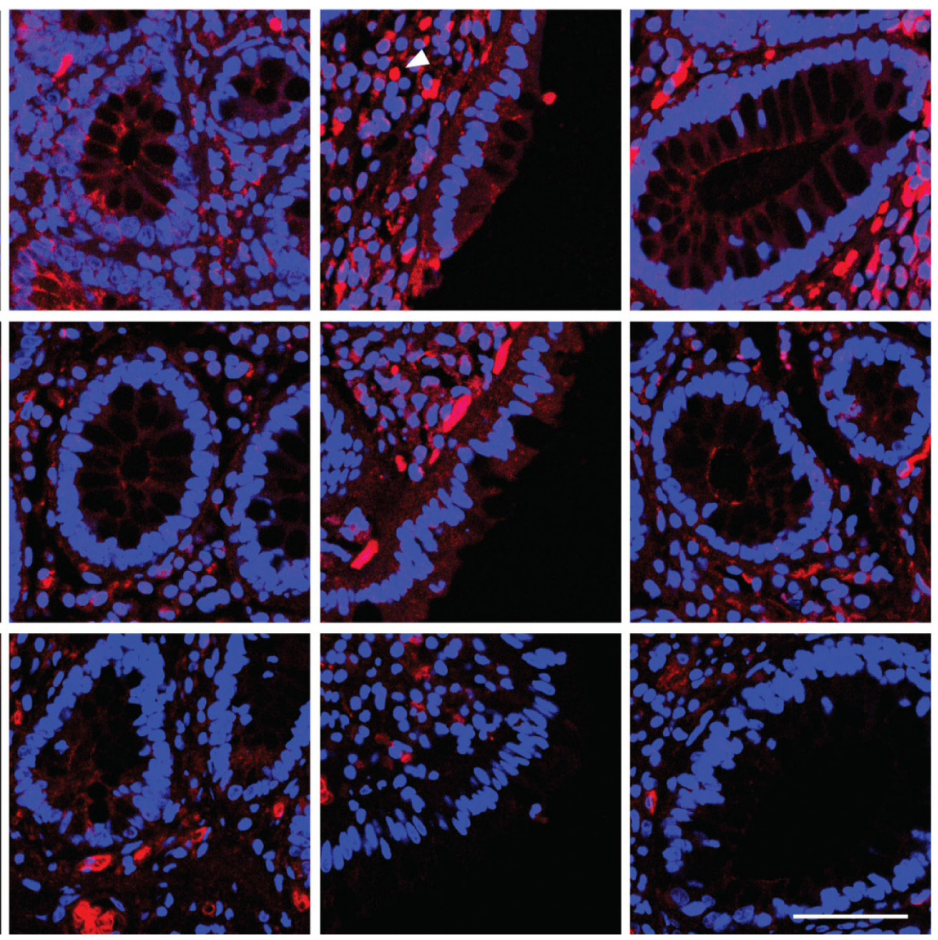

Figure I AQPI expression is reduced in the ileum of $C D$ patients.

Notes: (A) 3D structural model of human AQPI. The model is drawn as a cartoon representation; only amino acids in the entrance and water selection region are shown as sticks. The numbering is consistent with the human AQP sequence. Complete sequence identities between bovine AQPI (PDB ID IJ4N) and human AQPI, 3, and 7 are colored red, and nonidentical sequences are colored light blue. The water in the water channels is marked as W. (B) AQPI mRNA levels relative to GAPDH in the ileum, right and left colon. ***P<0.00I. (C) Immunofluorescense labeling of samples from control (upper panel), CD (middle panel), and UC (lower panel) with anti-AQPI antibody (red) and DAPI staining of the cell nuclei (blue). For AQPI in general, the labeling was not concentrated in the luminal epithelium, but mainly in the capillary endothelia and erythrocytes (arrowhead). Little or no staining was present in the mucosa epithelium. Scale bar: $50 \mu \mathrm{m}$.

Abbreviations: 3D, three-dimensional; AQP, aquaporin; CD, Crohn's disease; DAPI, 4',6-diamidino-2-phenylindole; GAPDH, glyceraldehyde 3-phosphate dehydrogenase; ID, identification number; mRNA, messenger RNA; PDB, Protein Data Bank; UC, ulcerative colitis.

\section{Differential expression of AQPs}

\section{$I, 3,7$, and 8 in intestinal mucosa of $C D$ and $U C$ patients}

AQP 1 and 3 mRNA levels were lower in the ileum of CD patients than in the ileum of UC patients $(P<0.001)$; AQP3 mRNA levels were lower in CD patients than in non-IBD controls $(P<0.001)$, whereas AQP1 mRNA levels were not significantly different in CD patients and non-IBD controls $(P=0.07)$ (Table S3).

AQP7 and AQP8 mRNA levels were lower in both ileum and colon biopsies from UC patients than from $\mathrm{CD}$ patients. AQP7 mRNA levels were lower in ileum as well as right and left colon biopsies from UC patients than from $\mathrm{CD}$ patients ( $P=0.002, P<0.001, P<0.001$, respectively). Similar results 
A

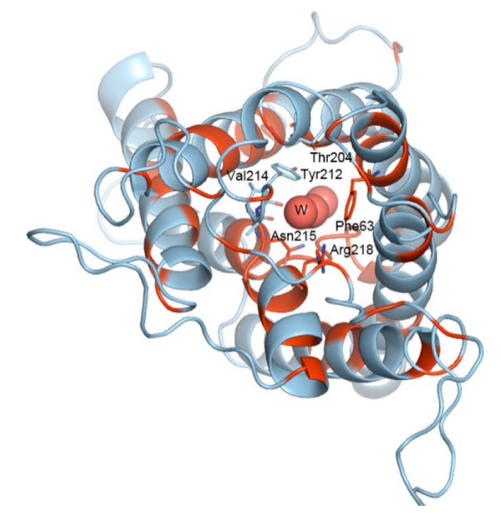

B

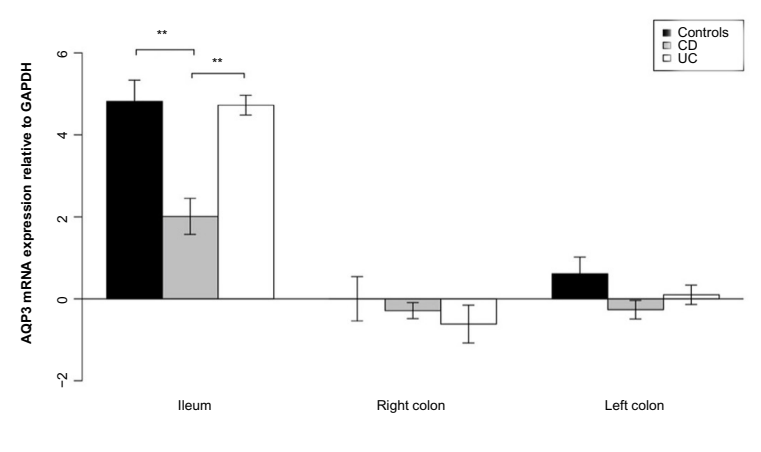

C Ileum surface
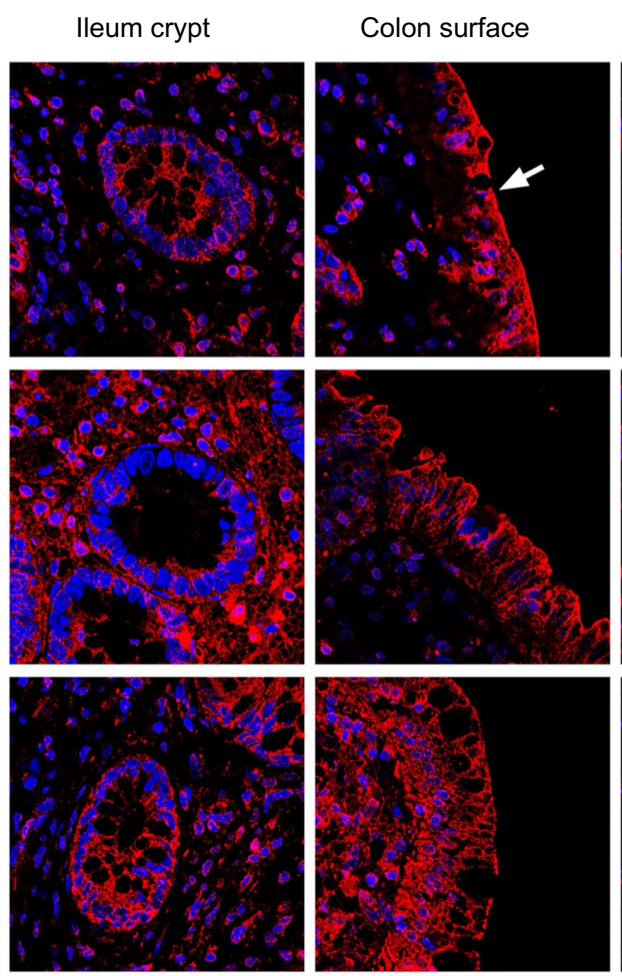

\section{Colon crypt}
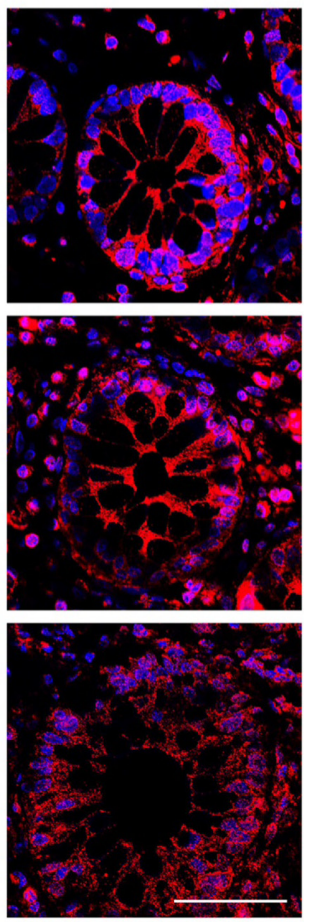

Figure $2 \mathrm{AQP} 3$ expression is reduced in the ileum of $C D$ patients.

Notes: (A) 3D structural model of human AQP3. The model is drawn as a cartoon representation; only amino acids in the entrance and water selection region are shown as sticks. The numbering is consistent with the individual human AQP sequence. Complete sequence identities between bovine AQPI (PDB ID IJ4N) and human AQPI, 3 , and 7 are colored red, and nonidentical sequences are colored light blue. The water in the water channels is marked as W. (B) AQP3 mRNA levels relative to GAPDH in the ileum, right and left colon. ${ }^{* * P}<0.01$. (C) Immunofluorescense staining with anti-AQP3 antibody (red) and DAPI staining of the cell nuclei (blue). Immunoreactivity of AQP3 was high in general. In the ileal biopsy of the control (upper panel) and the UC patient (lower panel), as well as in the sample from the colon of the control (upper panel), there was a distinct staining along the apical parts of the surface epithelium (arrows). The apical staining was reduced in the surface epithelium of the ileum biopsy from the CD patient (middle panel; arrowhead). Scale bar: $50 \mu \mathrm{m}$.

Abbreviations: 3D, three-dimensional; AQP, aquaporin; CD, Crohn's disease; DAPI, 4',6-diamidino-2-phenylindole; GAPDH, glyceraldehyde 3-phosphate dehydrogenase; ID, identification number; mRNA, messenger RNA; PDB, Protein Data Bank; UC, ulcerative colitis.

were obtained when ileum and left colon from UC patients were compared to those of non-IBD controls $(P=0.003, P<0.001$, respectively). AQP8 $\mathrm{mRNA}$ was less abundant in ileum as well as right and left colon biopsies from UC patients than from CD patients ( $P=0.005, P=0.008, P<0.001$, respectively) and less abundant in right and left colon in UC patients than in non-IBD controls ( $P=0.001, P<0.001$, respectively).

\section{AQPs detected by IF confocal microscopy}

Expression of AQPs 1, 3, 7, and 8 was confirmed at the protein level using IF confocal microscopy, as presented in Figures $1 \mathrm{C}-4 \mathrm{C}$. In agreement with the qRT-PCR results, AQPs 3, 7, and 8 were readily detected by IF in all bowel segments, and AQP1 was expressed at a moderate level in all samples, while AQPs 4, 5, and 9 were not detected in any samples tested. 
A

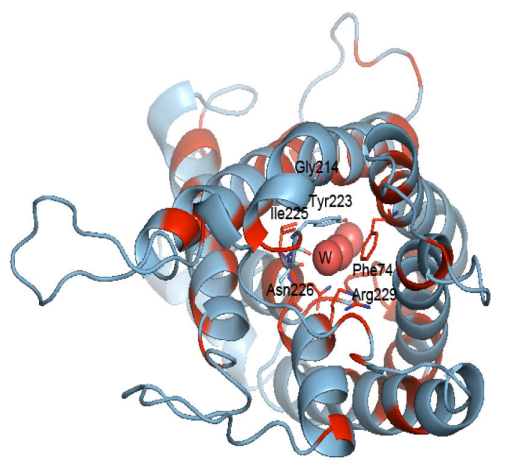

B

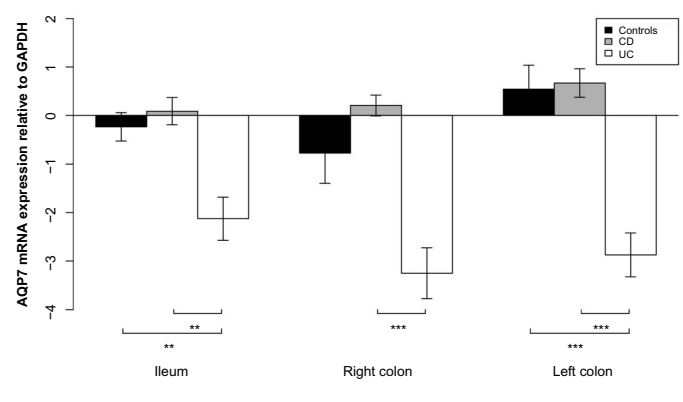

C

lleum surface

Ileum crypt
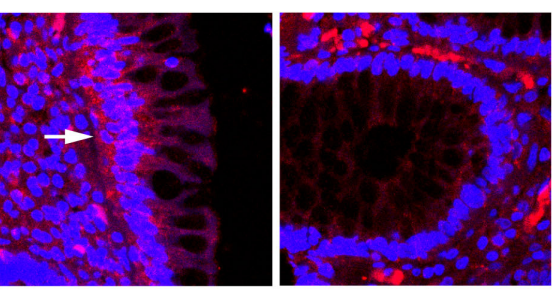

Colon surface

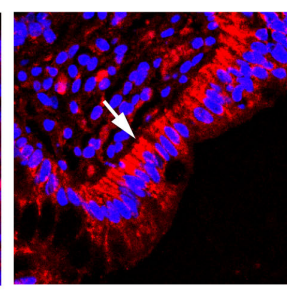

Colon crypt
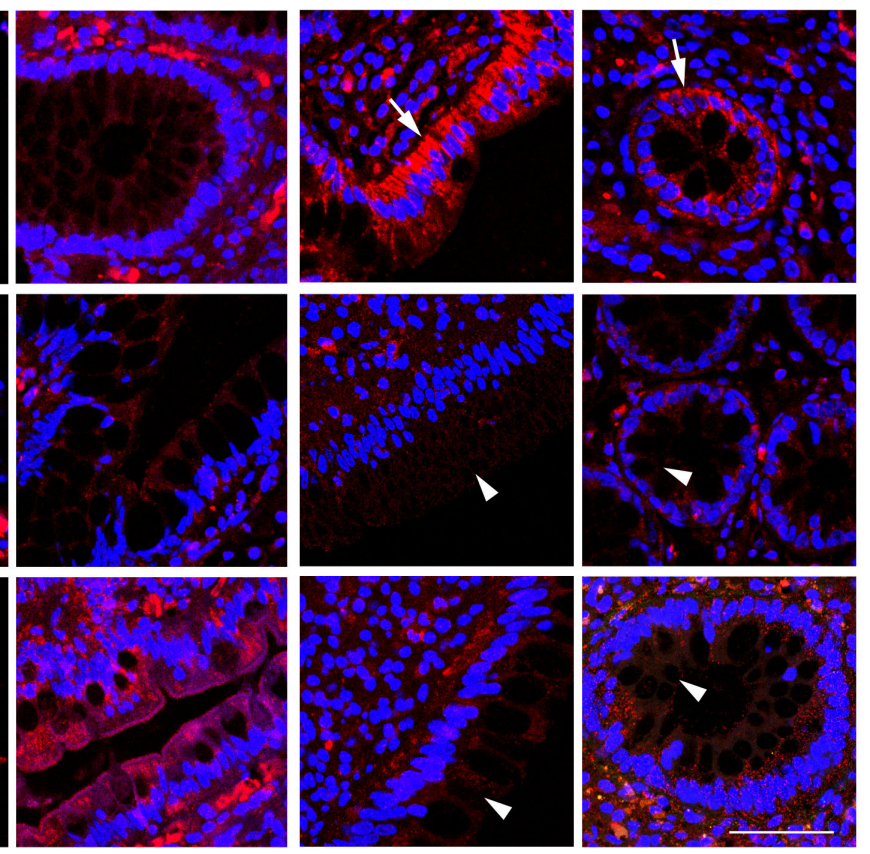

Figure 3 AQP7 expression is reduced in the ileum and colon of UC patients.

Notes: (A) 3D structural model of human AQP7. The model is drawn as a cartoon representation; only amino acids in the entrance and water selection region are shown as sticks. The numbering is consistent with the individual human AQP sequence. Complete sequence identities between bovine AQPI (PDB ID IJ4N) and human AQPI, 3, and 7 are colored red, and nonidentical sequences are colored light blue. The water in the water channels is marked as W. (B) AQP7 mRNA levels relative to GAPDH in the ileum, right and left colon. ${ }^{*} * P<0.01$, $* * * P<0.001$. (C) Immunofluorescense staining with anti-AQP7 antibody (red) and DAPI staining of the cell nuclei (blue): AQP7 staining was mainly present in the basolateral parts of surface epithelia in the ileum and colon (arrows), but also in the basolateral parts of colonic crypts (arrow). Especially in CD, and also in UC, the staining was weaker in both crypts and surface epithelia of the colon (arrowheads). Scale bar: $50 \mu \mathrm{m}$.

Abbreviations: 3D, three-dimensional; AQP, aquaporin; CD, Crohn's disease; DAPI, 4',6-diamidino-2-phenylindole; GAPDH, glyceraldehyde 3-phosphate dehydrogenase; ID, identification number; mRNA, messenger RNA; PDB, Protein Data Bank; UC, ulcerative colitis.

AQP1 was mainly located in the capillary endothelial cells and erythrocytes, but was not detected in the mucosal epithelium. It is not clear whether it is in the plasma membrane, in the cytosol, or nonspecific labeling.

The immunoreactivity of AQP3 was generally strong. In the ileal biopsy from the non-IBD control and the UC patient, as well as the in the sample from the colon of the non-IBD control, there was a distinct staining along the apical parts of the surface epithelium. The apical staining was reduced in the surface epithelium of the ileum biopsy from the $\mathrm{CD}$ patient (Figure 2C).
AQP7 staining was mainly present in the basolateral parts of surface epithelia in the ileum and colon, and also in the basolateral parts of colonic crypts. Especially in CD, but also in UC, the staining was weaker in both crypt and surface epithelia of the colon (Figure 3C). For AQP8, there was a distinct staining of the apical parts of the ileal and colonic surface epithelium, as well as the apical parts of colonic crypts. The signal was significantly decreased in intensity in the colonic samples of CD and UC. The distinct apical AQP8 labeling in the colonic crypt and surface epithelium was lost in the 
A

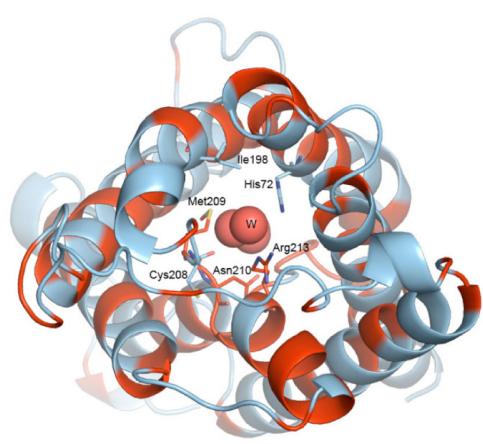

B

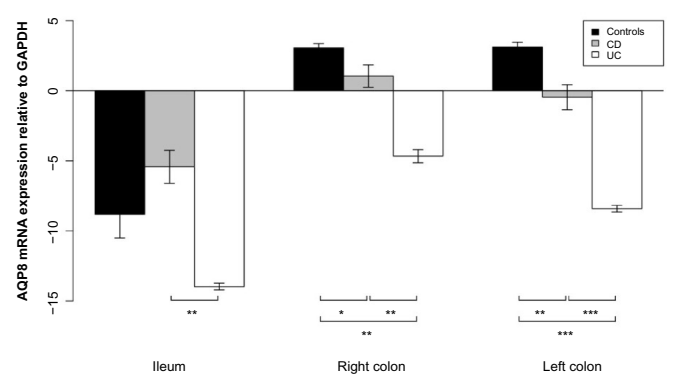

C

lleum surface

lleum crypt
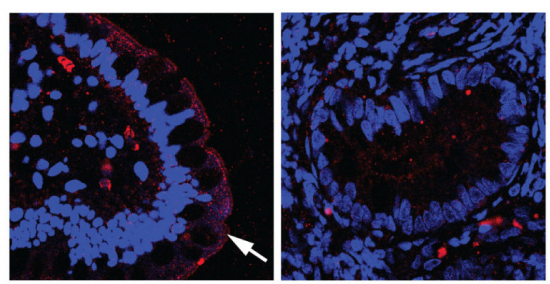

Colon surface
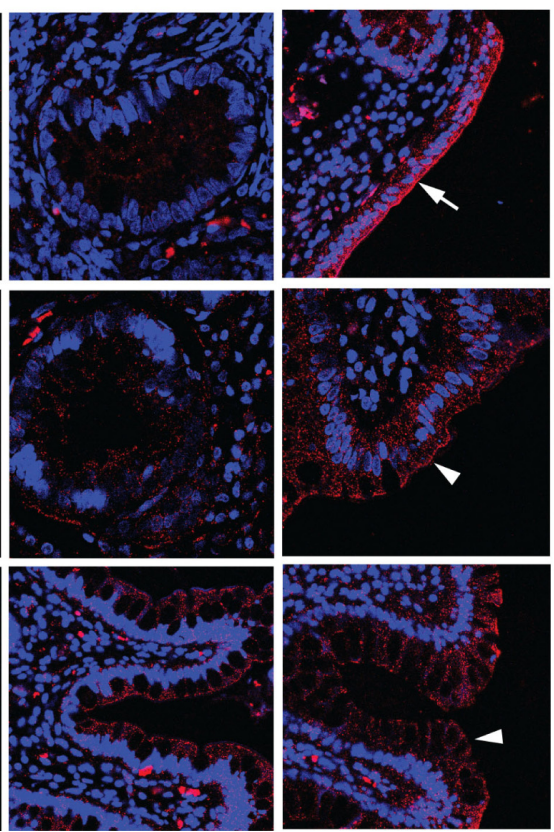

Colon crypt

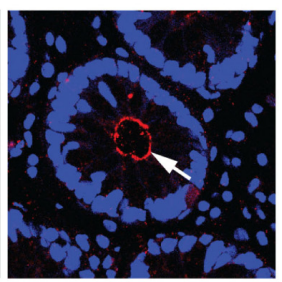

CD
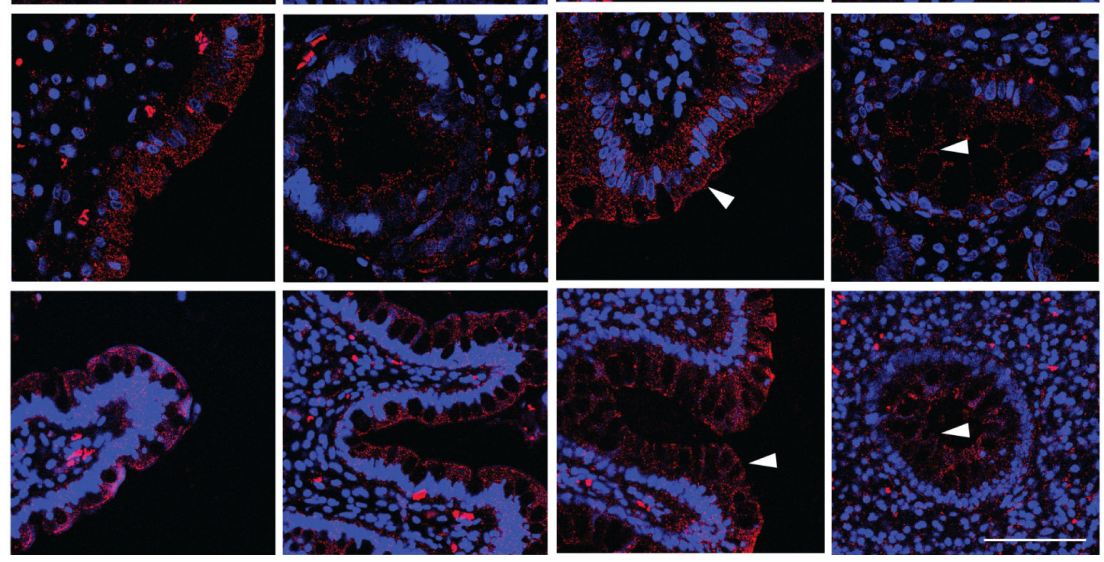

Figure 4 AQP8 expression is reduced in the ileum and colon of UC patients.

Notes: (A) 3D structural model of human AQP8. The model is drawn as a cartoon representation; only amino acids in the entrance and water selection region are shown as sticks. The numbering is consistent with the individual human AQP sequence. Complete sequence identities between human AQP8 and the template model human AQP5 (PDB ID 3D9S) are colored red, and nonidentical sequences are colored light blue. The water in the water channels is marked as W. (B) AQP8 mRNA levels relative to GAPDH in the ileum, right and left colon. $* P<0.05$, $* * P<0.01$, $* * * P<0.001$. (C) Immunofluorescense staining with anti-AQP8 antibody (red) and DAPI staining of the cell nuclei (blue). A distinct AQP8 staining is present at the apical parts of the ileal and colonic surface epithelium (arrows), as well as the apical parts of colonic crypts (arrow). In ileal samples, there was no difference in the degree of staining between the control and CD and UC, whereas the signal was significantly decreased in intensity in the colonic samples of CD and UC (arrowheads). The distinct apical AQP8 staining in the colonic crypts and surface epithelium was lost and a faint basolateral labeling appeared in the $\mathrm{CD}$ and UC samples. Scale bar: $50 \mu \mathrm{m}$.

Abbreviations: 3D, three-dimensional; AQP, aquaporin; CD, Crohn's disease; DAPI, 4',6-diamidino-2-phenylindole; GAPDH, glyceraldehyde 3-phosphate dehydrogenase; ID, identification number; mRNA, messenger RNA; PDB, Protein Data Bank; UC, ulcerative colitis.

CD and UC samples and was replaced with faint basolateral labeling, as shown in Figure 4C.

\section{Elevated TNF- $\alpha$ and interleukin-23A expression in CD}

TNF- $\alpha$ mRNA levels in biopsies from CD patients were higher in the ileum than in the colon $(P<0.001)$, as presented in Table 3; and interleukin-23A (IL-23A) mRNA levels were higher in the ileum than in the left colon $(P=0.04)$. Furthermore, TNF- $\alpha$ mRNA levels were higher in the ileum and left colon biopsies from CD patients than in UC patients $(P=0.001, P=0.003)$. IL-23 was expressed at a higher level in ileal biopsies from $C D$ patients than from UC patients $(P=0.01)$ or non-IBD controls $(P=0.03)$ (Table S3 and Figure 5).

\section{Elevated cyclooxygenase 2 expression in UC}

Cyclooxygenase 2(COX-2) was expressed at a higher level in the colon of UC patients than in the colon of CD or non-IBD 
Table 3 Comparison of aquaporin mRNA levels in the small and large bowel biopsies from CD and UC patients and non-IBD patients controls

\begin{tabular}{|c|c|c|c|c|c|c|c|c|c|}
\hline & \multicolumn{3}{|c|}{ Ileum vs right colon } & \multicolumn{3}{|c|}{ Ileum vs left colon } & \multicolumn{3}{|c|}{ Right vs left colon } \\
\hline & mRNA ratio & $P$-value & q-value & mRNA ratio & $P$-value & $q$-value & mRNA ratio & $P$-value & $q$-value \\
\hline \multicolumn{10}{|l|}{$C D$} \\
\hline AQPI & 5.49 & $<0.001$ & $<0.001$ & 2.64 & 0.002 & 0.009 & 0.48 & 0.002 & 0.01 \\
\hline AQP3 & 4.92 & $<0.001$ & $<0.001$ & 4.84 & $<0.00 \mathrm{I}$ & $<0.001$ & 0.98 & 0.45 & 0.71 \\
\hline AQP7 & 0.92 & 0.72 & 0.72 & 0.67 & 0.53 & 0.62 & 0.73 & 0.43 & 0.71 \\
\hline AQP8 & 0.01 & $<0.001$ & 0.01 & 0.03 & 0.004 & 0.07 & 2.85 & 0.11 & 0.46 \\
\hline COX-2 & 1.36 & 0.45 & 0.51 & $\mathrm{I} .48$ & 0.96 & 0.96 & 1.08 & 0.63 & 0.84 \\
\hline TNF- $\alpha$ & 3.22 & $<0.001$ & 0.002 & 2.20 & $<0.001$ & 0.01 & 0.68 & 0.28 & 0.71 \\
\hline IL-23A & 3.30 & 0.38 & 0.51 & 2.69 & 0.04 & 0.07 & 0.82 & 1.0 & 1.0 \\
\hline \multicolumn{10}{|l|}{ UC } \\
\hline AQPI & 12.85 & $<0.001$ & $<0.001$ & 6.64 & $<0.001$ & $<0.001$ & 0.52 & 0.11 & 0.51 \\
\hline AQP3 & 40.62 & $<0.001$ & $<0.001$ & 24.78 & $<0.001$ & $<0.001$ & 0.61 & 0.61 & 0.62 \\
\hline AQP7 & 2.18 & 0.04 & 0.07 & 1.68 & 0.3 & 0.38 & 0.77 & 0.64 & 0.68 \\
\hline AQP8 & 0.002 & 0.02 & 0.07 & 0.02 & 0.09 & 0.19 & 13.45 & 0.01 & 0.12 \\
\hline COX-2 & 0.78 & 0.12 & 0.15 & 0.43 & 0.12 & 0.19 & 0.54 & $0.4 I$ & 0.68 \\
\hline TNF- $\alpha$ & 1.54 & 0.41 & $0.4 I$ & 1.10 & 0.86 & 0.86 & 0.72 & $0.4 I$ & 0.68 \\
\hline IL-23A & 0.47 & 0.32 & 0.37 & 0.26 & 0.08 & 0.19 & 0.55 & 0.54 & 0.68 \\
\hline \multicolumn{10}{|l|}{ Controls } \\
\hline AQPI & 8.50 & 0.002 & 0.005 & 4.25 & 0.004 & 0.01 & 0.5 & 0.23 & 0.53 \\
\hline AQP3 & 28.25 & $<0.001$ & 0.001 & 18.44 & $<0.00 \mathrm{I}$ & $<0.001$ & 0.65 & 0.48 & 0.67 \\
\hline AQP7 & 1.46 & 0.31 & 0.52 & 0.59 & 0.24 & 0.48 & 0.40 & 0.04 & 0.28 \\
\hline AQP8 & 0.0003 & $<0.001$ & 0.002 & 0.0003 & $<0.001$ & 0.002 & 0.96 & 0.7 & 0.70 \\
\hline COX-2 & 0.76 & 0.54 & 0.66 & 0.93 & 0.65 & 0.75 & 1.23 & 0.43 & 0.67 \\
\hline TNF- $\alpha$ & 0.77 & 0.61 & 0.66 & 1.45 & 0.89 & 0.89 & 1.88 & 0.22 & 0.53 \\
\hline IL-23A & 1.61 & 0.1 & 0.22 & 1.36 & 0.58 & 0.75 & 0.85 & 0.7 & 0.70 \\
\hline
\end{tabular}

Note: $m R N A$ levels detected by $q R T$-PCR are given as mRNA ratios calculated from delta delta $C_{T}$ values with $P$-values and multiple testing adjusted $P$-values ( $q$-values). Abbreviations: mRNA, messenger RNA; CD, Crohn's disease; UC, ulcerative colitis; IBD, inflammatory bowel disease; AQP, aquaporin; COX-2, cyclooxygenase 2; TNF- $\alpha$, tumor necrosis factor- $\alpha$; IL, interleukin; qRT-PCR, quantitative real-time polymerase chain reaction; vs, versus.

controls $(P=0.02$ and $P=0.003$ for right colon and $P=0.003$ and $P<0.001$ for left colon, respectively) as shown in Table S3 and Figure 5. COX-2 was also expressed at a higher level in the ileum of UC patients than in the ileum of non-IBD patients $(P=0.014)$.

\section{Discussion}

This is the first description of concurrent AQP expression and inflammation patterns in human gut biopsy samples from well-characterized IBD patients and controls. The results

Table 4 Summary of the general trends in AQP expression detected by mRNA levels

\begin{tabular}{lllll}
\hline & AQPI & AQP3 & AQP7 & AQP8 \\
\hline CD & & & & \\
Ileum & $\downarrow$ & $\downarrow$ & - & - \\
Colon & - & - & - & - \\
UC & & & & \\
Ileum & - & - & $\downarrow$ & $\downarrow$ \\
Colon & - & - & $\downarrow$ & $\downarrow$ \\
\hline
\end{tabular}

Abbreviations: mRNA, messenger RNA; CD, Crohn's disease; UC, ulcerative colitis; AQP, aquaporin; -, no trend. clearly demonstrate reduced and differential expression of AQPs in $\mathrm{CD}$ and UC as compared to controls, providing insight into the potential role of AQPs in the pathology and/ or inflammation associated with IBD. The present study is a systematic cross-sectional analysis of AQP expression in nontreated early IBD patients whose subgroup status is well characterized. Notably, AQP expression profiles were statistically different in CD and UC patients relative to non-IBD controls, suggesting differential gene expression associated with these diseases.

The main conclusions from the study are as follows: 1) $\mathrm{AQP} 1, \mathrm{AQP} 3, \mathrm{AQP} 7$, and $\mathrm{AQP} 8$ are the predominant $\mathrm{AQPS}$ in the human distal ileum and colon; 2) AQP1 and AQP3 mRNA levels are reduced in the ileum of CD patients; 3) AQP7 and AQP8 mRNA levels are reduced in the ileum and colon of UC patients; and 4) there is a reduction of apical AQP8 immunolabeling in the colonic surface epithelium and crypts of the IBD samples.

Very few studies have analyzed expression of AQPs in human tissues in vivo. A summary of key properties of AQPs is provided in Table 5. Silberstein et al demonstrated that AQP3 
Table 5 Summary of key properties of AQPs

\begin{tabular}{|c|c|c|c|c|c|}
\hline Aquaporins & Organism & Main location & $\begin{array}{l}\text { Our findings } \\
\text { in the GI tract }\end{array}$ & Comment & References \\
\hline AQPO & Mammals & Lens & na & AQP & 57 \\
\hline AQPI & Mammals & $\begin{array}{l}\text { Red blood cells } \\
\text { Kidney } \\
\text { Lung } \\
\text { Vascular endothelium } \\
\text { Brain, eye: glial cells } \\
\text { Neurons }\end{array}$ & $\begin{array}{l}\text { Reduced amounts } \\
\text { in ileum in } C D\end{array}$ & AQP & $\begin{array}{l}58 \\
59 \\
60 \\
\text { This study }\end{array}$ \\
\hline AQP2 & Mammals & $\begin{array}{l}\text { Kidney } \\
\text { Vas deferens } \\
\text { Neurons }\end{array}$ & na & AQP & $\begin{array}{l}82 \\
61 \\
62\end{array}$ \\
\hline AQP3 & Mammals & $\begin{array}{l}\text { Kidney } \\
\text { Skin } \\
\text { Lung } \\
\text { Eye } \\
\text { Colon }\end{array}$ & $\begin{array}{l}\text { Reduced amounts } \\
\text { in ileum in } C D\end{array}$ & $\begin{array}{l}\text { Aquaglyceroporin } \\
\text { Water, glycerol, urea }\end{array}$ & $\begin{array}{l}63 \\
\text { This study }\end{array}$ \\
\hline AQP4 & Mammals & $\begin{array}{l}\text { Brain, muscle, } \\
\text { kidney, lung, stomach, } \\
\text { small intestine } \\
\text { Neurons } \\
\text { Vascular endothelium }\end{array}$ & - & $\begin{array}{l}\text { AQP } \\
\text { Main AQP in the } \\
\text { brain }\end{array}$ & $\begin{array}{l}64 \\
65 \\
66\end{array}$ \\
\hline AQP5 & Mammals & $\begin{array}{l}\text { Salivary/lacrimal gland } \\
\text { Sweat gland } \\
\text { Lung } \\
\text { Cornea }\end{array}$ & - & AQP & $\begin{array}{l}67 \\
68 \\
27\end{array}$ \\
\hline AQP6 & Mammals & Kidney & na & $\begin{array}{l}\text { AQP } \\
\text { Anion channel }\end{array}$ & 7 \\
\hline AQP7 & Mammals & $\begin{array}{l}\text { Adipose tissue } \\
\text { Kidney } \\
\text { Testis }\end{array}$ & $\begin{array}{l}\text { Reduced amounts } \\
\text { in ileum and } \\
\text { colon in UC }\end{array}$ & $\begin{array}{l}\text { Aquaglyceroporin } \\
\text { Water, glycerol, } \\
\text { urea, arsenite }\end{array}$ & $\begin{array}{l}69 \\
\text { This study }\end{array}$ \\
\hline AQP8 & Mammals & $\begin{array}{l}\text { Testis, kidney, liver, } \\
\text { pancreas, small } \\
\text { intestine, colon }\end{array}$ & $\begin{array}{l}\text { Reduced amounts } \\
\text { in ileum and } \\
\text { colon in UC }\end{array}$ & $\mathrm{AQP}$ & $\begin{array}{l}70 \\
\text { This study }\end{array}$ \\
\hline AQP9 & Mammals & $\begin{array}{l}\text { Liver, leukocytes, } \\
\text { brain, testis }\end{array}$ & - & $\begin{array}{l}\text { Aquaglyceroporin } \\
\text { Water, glycerol, } \\
\text { urea, arsenite }\end{array}$ & 71 \\
\hline AQPIO & Mammals & $\begin{array}{l}\text { Small intestine } \\
\text { Kidney }\end{array}$ & na & $\begin{array}{l}\text { Aquaglyceroporin } \\
\text { Water, glycerol, urea }\end{array}$ & $\begin{array}{l}72 \\
6\end{array}$ \\
\hline AQPII & Mammals & Kidney ER & na & $\begin{array}{l}\text { Super-AQP } \\
\text { Divergent NPA motif, } \\
\text { sign cysteine }\end{array}$ & 73 \\
\hline AQPI2 & Mammals & Pancreas & na & $\begin{array}{l}\text { Super-AQP } \\
\text { Divergent NPA motif, } \\
\text { sign cysteine }\end{array}$ & 74 \\
\hline AQPZ & $\begin{array}{l}\text { E. coli, } \\
\text { Mycobacterium abscessus* }\end{array}$ & na & na & AQP & $\begin{array}{l}75 \\
\text { This study* }\end{array}$ \\
\hline GlpF & $\begin{array}{l}\text { E. coli, } \\
\text { Haemophilus influenzae, } \\
\text { Streptococcus pyogenes* }\end{array}$ & na & na & Aquaglyceroporin & $\begin{array}{l}75 \\
76 \\
\text { This study* }\end{array}$ \\
\hline AQYI/2 & Yeast & na & na & AQP & $\begin{array}{l}77 \\
78\end{array}$ \\
\hline GLPYI/2 & Yeast & na & na & Aquaglyceroporin & 79 \\
\hline $\begin{array}{l}\mathrm{PIPs} / \mathrm{TIPs} / \\
\mathrm{NIPs} / \mathrm{SIPs}\end{array}$ & Plants & na & na & $\mathrm{AQP}$ & $\begin{array}{l}80 \\
81\end{array}$ \\
\hline
\end{tabular}

Note: - indicates not detected above threshold in the gut.

Abbreviations: AQP, aquaporin; AQPZ, aquaporin-related pore; na, not applicable; E. coli, Escherichia coli; ER, endoplasmic reticulum; glpF, glycerol facilitator; GI, gastrointestinal; NPA, asparagine-proline-alanine; CD, Crohn's disease; NIPs, nodulin 26-like intrinsic membrane proteins; PIPs, plasma membrane intrinsic proteins; SIPs, small basic intrinsic proteins; TIPs, tonoplast intrinsic proteins; UC, ulcerative colitis; AQYI/2, yeast aquaporin; GLPYI/2, yeast glycerol facilitation-like protein. 

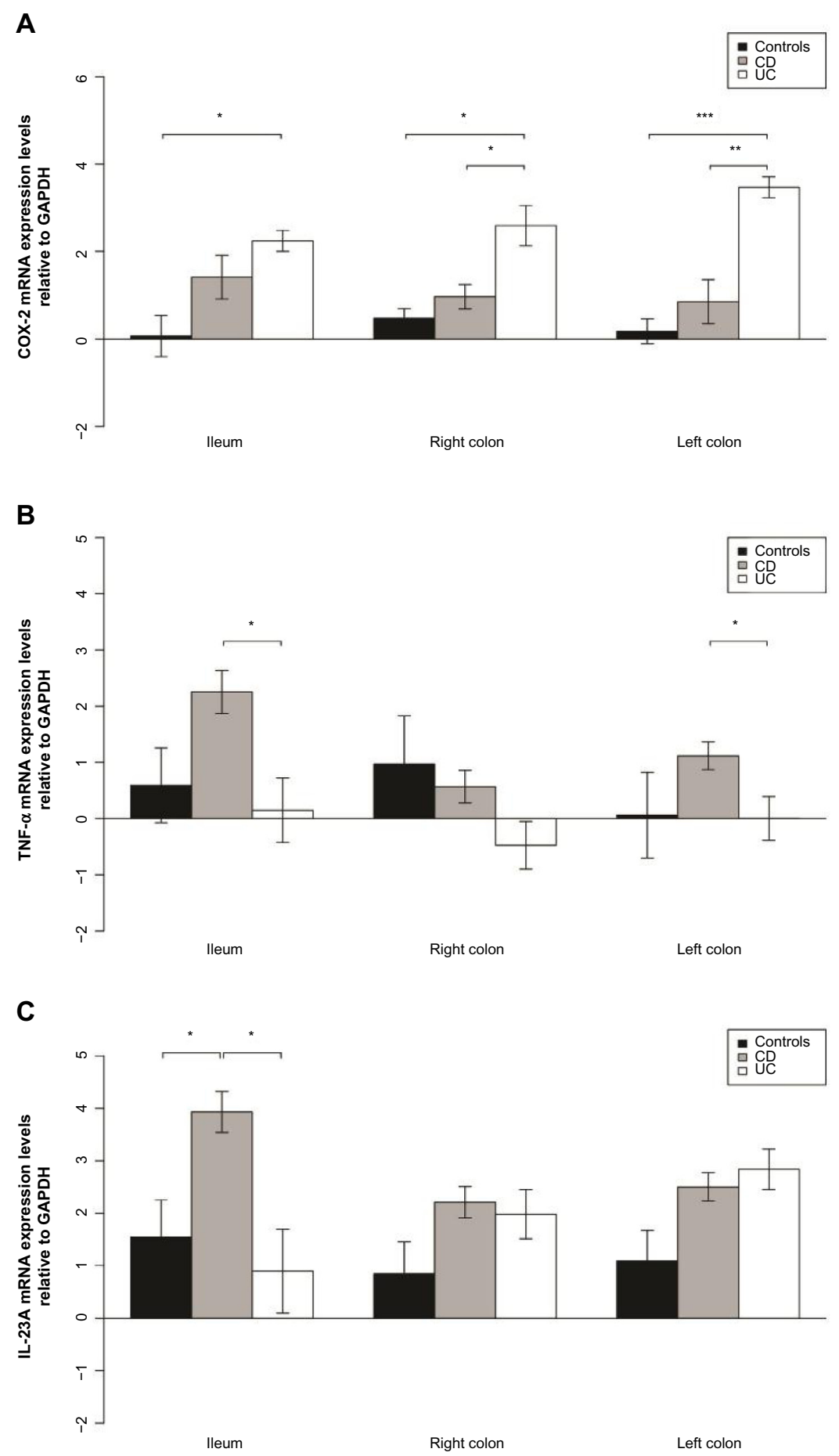

Figure 5 Elevated COX-2 expression in UC and TNF- $\alpha$ and IL-23 expression in CD.

Notes: (A) COX-2 mRNA levels relative to GAPDH in the ileum, right and left colon. $* P<0.05$, $* * P<0.01$, $* * * P<0.00$ I. (B) TNF- $\alpha$ mRNA levels relative to GAPDH in the ileum, right and left colon. ${ }^{*} P<0.05$. (C) IL-23A mRNA levels relative to GAPDH in the ileum, right and left colon. $* P<0.05$.

Abbreviations: CD, Crohn's disease; UC, ulcerative colitis; GAPDH, glyceraldehyde 3-phosphate dehydrogenase; IL, interleukin; mRNA, messenger RNA; COX-2, cyclooxygenase 2 ; TNF- $\alpha$, tumor necrosis factor- $\alpha$.

is expressed apically in the surface epithelium of the normal human colon, ${ }^{34}$ which is consistent with our observation that AQP3 is abundant in the epithelia of the mucosal surface and the crypts of the normal human colon. Planell et al detected abnormal AQP3 and AQP8 levels in UC patients in remission; ${ }^{23}$ however, that study addressed lasting epithelial cell alterations and the effect of treatment on UC but did not include CD patients.

Our study is the first to demonstrate high AQP3 mRNA levels in the human ileum and to show that AQP3 mRNA levels 
and protein levels are significantly reduced in patients with CD. Reduced AQP 1, 3, 7, and 8 expressions might be due to a negative feedback regulation during inflammation, to protect against excessive water loss. Furthermore, reduced AQP3 and AQP8 mRNA levels in IBD colon might alleviate oxidative stress in the diseased colon, because both AQP3 and AQP8 transport $\mathrm{H}_{2} \mathrm{O}_{2},{ }^{10}$ which is increased in the inflamed mucosa in $\mathrm{CD}$ and UC patients, possibly due to increased bacterial load. ${ }^{35,36}$ In general, the AQP 3D structures depicted elucidate the AQP structural motifs and signatures and highlight the remarkable evolutionary conservation of the different AQPs expressed in the gut. The 3D AQP isoform models may also indicate how future studies should be focused.

Although a differential expression of AQPs 7 and 8 was noted in UC samples, evidence for differential expression of these AQPs in CD colitis samples was not demonstrated. When data were stratified according to subgroups (ileitis, colitis, ileocolitis) of CD, differences in expression of AQPs did not reach statistical significance. Future studies should involve a larger number of $\mathrm{CD}$ patients, and $\mathrm{AQP}$ expression should be compared in patients with specific CD subtypes, namely, $\mathrm{CD}$ with colitis and CD with ileitis with or without colitis.

AQPs 4, 5, and 9 were expressed below the limit of detection by qRT-PCR and IF in all the human patient groups investigated. In contrast, expression of these AQPs has been readily detected in the rodent gut. ${ }^{13,37}$ Because only a few studies have analyzed AQP expression in the human gut, it is possible that these AQPs might be expressed in segments of the human bowel not studied here or in deeper layers of the intestinal wall. Moreover, lack of detection of AQP9 mRNA was surprising because AQP9 has been previously shown to be expressed in leukocytes and upregulated in inflammatory disease. ${ }^{38,39}$ This discrepancy should be addressed in future studies. Matsuzaki et al have shown the expression of AQP3 in absorptive ileum cells as well as in epithelial cells in the distal colon and rectum of rats. ${ }^{40}$

In humans, AQP3 is thought to facilitate absorption of water by colonic surface cells ${ }^{34}$ and promote enterocyte proliferation. ${ }^{41}$ In our study, we observed a distinct expression of AQP3 in the apical lining of the surface epithelium in both ileum and colon in the control samples. However, the distinct apical labeling observed in the control samples was reduced in the surface epithelium of CD samples from the ileum. Loss of distinct apical immunolabeling was also observed for AQP8 in the colonic crypts and surface epithelium of the samples with UC and CD. These observations might indicate a possible disruption of the cellular polarity as a result of IBD.
Interestingly, in a murine model of Citrobacter rodentium-induced colitis, Guttman et al demonstrated that AQP2 and AQP3 migrate from the membrane to the cytoplasm. ${ }^{42}$ Tsujikawa et al have demonstrated that rat AQPs 1, 3, 7, and 8, but not AQP4, are upregulated in the residual ileum and colon following small bowel resection. ${ }^{43}$ Assuming bidirectional osmotically driven flow through AQPs, upregulation of these AQPs might directly compensate for the lack of proximal water absorption due to small bowel resection. Fischer et al postulated that AQP8 is a marker of normal proliferating colonic epithelial cells and suggested that these cells transport fluid in the colon. ${ }^{44}$ Te Velde et al have reported that AQP8 is downregulated in three colitis mouse models and suggested that downregulation of AQPs in this context could protect against oxidative stress. ${ }^{36}$

Data presented here corroborate with previous human studies showing that AQP7 and AQP8 are downregulated in UC. Hardin et al have shown that AQP7 and AQP8 are downregulated in $\mathrm{CD}, \mathrm{UC}$, and infectious colitis, and reported very weak expression of AQP4 in the human colon. ${ }^{45}$ Notably, Zahn et al detected a decreased AQP8 expression in ileum, but increased AQP8 expression in colon in mucosal biopsies from noninflamed regions. ${ }^{46}$ The authors speculated that there could be a downregulation of AQP8 expression at the very beginning of inflammation, as in Hardin's study, followed by a compensatory increase in expression. Wang and Hou reported the downregulation of AQP8 in patients with diarrhea-dominated IBS. ${ }^{47}$

The mucosal expression of the aquaglyceroporins AQP3 and AQP7 could reflect the requirement for and organ-specific functionality of water and solute transport in the gut; furthermore, if glycerol is in fact transported via these channels in the human gut, it might at least in part explain extreme weight loss in some IBD patients. In a cellular model, Zhang et al have demonstrated that knockdown of AQP3 might lead to bacterial translocation as a result of increased paracellular permeability leading to a defective intestinal barrier function. ${ }^{48}$ Given that AQP3 is expressed at relatively low levels in the terminal ileum of the CD patients studied here, it is conceivable that CD pathology is exacerbated because of increased paracellular permeability, combined with a defect in bacterial sensing. In this regard, it is noteworthy that Tanaka et al have shown that AQP3 expression was induced by corticosteroids in a human airway epithelial cell line,${ }^{49}$ consistent with the fact that oral budesonide is an effective treatment of $\mathrm{CD}$ in the terminal ileum. 
In inflamed tissue from patients with colitis, AQP 7 and AQP 8 expression decreased and the location of AQP8 in the colonic crypt and surface epithelium seemed to shift from apical to basolateral (Figure 4). If high levels of AQP 7 (and AQP 8) normally promote secretion of mucus, this could explain the characteristic lack of mucus in the UC colon. Loss of the distinct apical localization of AQP3 and AQP8 in the colonic surface epithelium and crypts of the UC and CD samples might indicate disruption of the epithelial polarity, which can lead to intestinal barrier dysfunction. ${ }^{50}$

$\mathrm{CD}$ and $\mathrm{UC}$ have traditionally been identified as T helper (Th) cell 1-driven and Th2-driven diseases, respectively, but recent studies demonstrate that IL-23- and Th17-dependent inflammation play a role in both diseases. ${ }^{51} \mathrm{TNF}-\alpha$ is also a well-established marker of inflammation in IBD, and anti-TNF- $\alpha$ therapy is used as treatment for both disease entities. ${ }^{52}$ Previous studies have demonstrated conflicting results regarding a higher expression of TNF- $\alpha$ in CD than UC. ${ }^{53,54}$ As for the IL-23 expression patterns, little is known in IBD. ${ }^{55}$ The increased expression of these proinflammatory markers may suggest a direct or indirect relationship between inflammation and the patterns of AQP expression detected in the present study. We were not able to show a correlation between the expression of the inflammatory markers and clinical or endoscopic disease activity, most probably due to the small number of patients in each disease group.

We hypothesize that changes in AQP expression are linked to specific IBD subtypes. Reduced AQP1 and AQP3 mRNA levels in the ileum of CD could be a primary event leading to reduced absorption of water and glycerol in the small bowel, and this could cause diarrhea and poor nutritional status. Reduced AQP mRNA levels might be a consequence of inflammation or rather a defense mechanism against oxidative stress. It is also possible that inflammationrelated cell death and loss of surface epithelial cells, especially in UC, indirectly leads to apparent reduction in levels of AQP mRNA.

\section{Conclusion}

This study has demonstrated that human AQPs are differentially expressed in the small and large bowel mucosal epithelia of untreated CD and UC patients, suggesting a potential, distinct role for these membrane channels in transporting water and solutes in the human intestinal tract, and that their dysregulation might play a role in IBD. These findings link gut inflammation and water/solute homeostasis and also challenge the traditional concept of gut permeability and bidirectional water/glycerol transit. The results have clear implications for understanding CD and UC pathogenesis and future IBD diagnostics and therapeutics.

\section{Author contributions}

PR and TT conceived the study; PR, TT, and MAM were involved in study concept and design; PR, LKL, MS, AR, $\mathrm{MHV}$, and MAM acquired the data; JPM performed the 3D structural modeling of AQPs; PR, LKL, SAF, MS, SN, AR, MHV, MAM, and TT contributed to experimental analysis and/or interpretation of data; $\mathrm{SN}$ was responsible for statistical analysis; and PR, AR, MHV, MAM, JPM, and TT drafted the manuscript. All authors were involved in critical revision of the manuscript for important intellectual content.

\section{Acknowledgments}

We thank professor Solveig Norheim Andersen, Department of Pathology, Akershus University Hospital, for providing the histological samples used in this study; professor Torleiv Rognum, Department of Forensic Medicine and Toxicology, Oslo University Hospital, for providing human samples for control experiments; Karin Helmersen, EpiGen Institute, Akershus University Hospital, for expert technical assistance; and Carina Knudsen, Institute of Basic Medical Sciences, University of Oslo, for the artwork. This work was supported by grants from HelseSør RHF (the IBSEN II study), an Akershus University Hospital grant for strategic research, Oslo University Hospital (Rikshospitalet), and the Research Council of Norway by Centre of Excellence grant \#145977 (Centre for Molecular Biology and Neuroscience [CMBN]) to TT and MAM as well as Research Council of Norway FRIMEDBIO projects \#204747 to TT and \#486454 to JPM.

\section{Disclosure}

The authors report no conflict of interest in this work.

\section{References}

1. Haskell H, Andrews CW Jr, Reddy SI, et al. Pathologic features and clinical significance of "backwash" ileitis in ulcerative colitis. Am J Surg Pathol. 2005;29:1472-1481.

2. He F, Peng J, Deng XL, et al. Mechanisms of tumor necrosis factor-alpha-induced leaks in intestine epithelial barrier. Cytokine. 2012;59:264-272.

3. Verkman AS. Aquaporins in clinical medicine. Annu Rev Med. 2012;63:303-316.

4. Nielsen S, Agre P. The aquaporin family of water channels in kidney. Kidney Int. 1995;48:1057-1068.

5. Agre P, King LS, Yasui M, et al. Aquaporin water channels - from atomic structure to clinical medicine. J Physiol. 2002;542:3-16.

6. Ishibashi K. New members of mammalian aquaporins: AQP10-AQP12. Handb Exp Pharmacol. 2009;190:251-262. 
7. Yasui M, Hazama A, Kwon TH, Nielsen S, Guggino WB, Agre P. Rapid gating and anion permeability of an intracellular aquaporin. Nature. 1999;402:184-187.

8. Jahn TP, Møller AL, Zeuthen T, et al. Aquaporin homologues in plants and mammals transport ammonia. FEBS Lett. 2004;574:31-36.

9. Bienert GP, Moller AL, Kristiansen KA, et al. Specific aquaporins facilitate the diffusion of hydrogen peroxide across membranes. $J$ Biol Chem. 2007;282:1183-1192.

10. Miller EW, Dickinson BC, Chang CJ. Aquaporin-3 mediates hydrogen peroxide uptake to regulate downstream intracellular signaling. Proc Natl Acad Sci U S A. 2010;107:15681-15686.

11. Saparov SM, Liu K, Agre P, Pohl P. Fast and selective ammonia transport by aquaporin-8. J Biol Chem. 2007;282:5296-5301.

12. Agemark M, Kowal J, Kukulski W, et al. Reconstitution of water channel function and 2D-crystallization of human aquaporin 8. Biochim Biophys Acta. 2012;1818:839-850.

13. Ishibashi K, Hara S, Kondo S. Aquaporin water channels in mammals. Clin Exp Nephrol. 2009;13:107-117.

14. Krane CM, Fortner CN, Hand AR, et al. Aquaporin 5-deficient mouse lungs are hyperresponsive to cholinergic stimulation. Proc Natl Acad Sci U S A. 2001;98:14114-14119.

15. King LS, Yasui M, Agre P. Aquaporins in health and disease. Mol Med Today. 2000;6:60-65.

16. Ferri D, Mazzone A, Liquori GE, Cassano G, Svelto M, Calamita G. Ontogeny, distribution, and possible functional implications of an unusual aquaporin, AQP8, in mouse liver. Hepatology. 2003;38: 947-957.

17. Ishibashi K, Tanaka Y, Morishita Y. The role of mammalian superaquaporins inside the cell. Biochim Biophys Acta. 2014;1840(5): 1507-1512.

18. Engel A, Stahlberg H. Aquaglyceroporins: channel proteins with a conserved core, multiple functions, and variable surfaces. Int Rev Cytol. 2002;215:75-104.

19. Magni F, Chinello C, Raimondo F, Mocarelli P, Kienle MG, Pitto M. AQP1 expression analysis in human diseases: implications for proteomic characterization. Expert Rev Proteomics. 2008;5:29-43.

20. Hachez C, Chaumont F. Aquaporins: a family of highly regulated multifunctional channels. Adv Exp Med Biol. 2010;679:1-17.

21. Ma T, Verkman AS. Aquaporin water channels in gastrointestinal physiology. J Physiol. 1999;517(pt 2):317-326.

22. Verkman AS. Aquaporins: translating bench research to human disease J Exp Biol. 2009;212:1707-1715.

23. Planell N, Lozano JJ, Mora-Buch R, et al. Transcriptional analysis of the intestinal mucosa of patients with ulcerative colitis in remission reveals lasting epithelial cell alterations. Gut. 2013;62:967-976.

24. Lennard-Jones JE. Classification of inflammatory bowel disease. Scand J Gastroenterol Suppl. 1989;170:2-6.

25. Ricanek P, Brackmann S, Perminow G, et al; IBSEN II Study Group. Evaluation of disease activity in IBD at the time of diagnosis by the use of clinical, biochemical, and fecal markers. Scand J Gastroenterol. 2011;46:1081-1091

26. Sui H, Han BG, Lee JK, Walian P, Jap BK. Structural basis of waterspecific transport through the AQP1 water channel. Nature. 2001;414: 872-878.

27. Horsefield R, Nordén K, Fellert M, et al. High-resolution x-ray structure of human aquaporin 5. Proc Natl Acad Sci U SA. 2008;105: 13327-13332.

28. Sali A, Blundell TL. Comparative protein modelling by satisfaction of spatial restraints. J Mol Biol. 1993;234:779-815.

29. Eswar N, Webb B, Marti-Renom MA et al. Comparative protein structure modeling using Modeller. Curr Protoc Bioinformatics. 2006; Chapter 5:Unit 5.6.

30. Matsuzaki T, Tajika Y, Ablimit A, Aoki T, Hagiwara H, Takata K. Aquaporins in the digestive system. Med Electron Microsc. 2004;37: 71-80.

31. Schmittgen TD, Livak KJ. Analyzing real-time PCR data by the comparative C(T) method. Nat Protoc. 2008;3:1101-1108.

32. Benjamini Y, Hochberg Y. Controlling the false discovery rate: a practical and powerful approach to multiple testing. J R Stat Soc B. 1995;57:289-300.
33. Development Core Team. R: A Language and Environment for Statistical Computing. Vienna, Austria: R Foundation for Statistical Computing, ISBN 3-900051-07-0; 2011.

34. Silberstein C, Kierbel A, Amodeo G, et al. Functional characterization and localization of AQP3 in the human colon. Braz J Med Biol Res. 1999;32:1303-1313.

35. Strus M, Janczyk A, Gonet-Surowka A, et al. Effect of hydrogen peroxide of bacterial origin on apoptosis and necrosis of gut mucosa epithelial cells as a possible pathomechanism of inflammatory bowel disease and cancer. J Physiol Pharmacol. 2009;60(Suppl 6):55-60.

36. Te Velde AA, Pronk I, de Kort F, Stokkers PC. Glutathione peroxidase 2 and aquaporin 8 as new markers for colonic inflammation in experimental colitis and inflammatory bowel diseases: an important role for H2O2? Eur J Gastroenterol Hepatol. 2008;20:555-560.

37. Thi MM, Spray DC, Hanani M. Aquaporin-4 water channels in enteric neurons. J Neurosci Res. 2008;86:448-456.

38. Mesko B, Poliska S, Szegedi A, et al. Peripheral blood gene expression patterns discriminate among chronic inflammatory diseases and healthy controls and identify novel targets. BMC Med Genomics. 2010;3:15.

39. Ishibashi K, Kuwahara M, Gu Y, Tanaka Y, Marumo F, Sasaki S. Cloning and functional expression of a new aquaporin (AQP9) abundantly expressed in the peripheral leukocytes permeable to water and urea, but not to glycerol. Biochem Biophys Res Commun. 1998;244(1): 268-274.

40. Matsuzaki T, Suzuki T, Koyama H, Tanaka S, Takata K. Water channel protein AQP3 is present in epithelia exposed to the environment of possible water loss. J Histochem Cytochem. 1999;47:1275-1286.

41. Thiagarajah JR, Zhao D, Verkman AS. Impaired enterocyte proliferation in aquaporin-3 deficiency in mouse models of colitis. Gut. 2007;56: $1529-1535$.

42. Guttman JA, Samji FN, Li Y, Deng W, Lin A, Finlay BB. Aquaporins contribute to diarrhoea caused by attaching and effacing bacterial pathogens. Cell Microbiol. 2007;9:131-141.

43. Tsujikawa T, Itoh A, Fukunaga T, Satoh J, Yasuoka T, Fujiyama Y. Alteration of aquaporin mRNA expression after small bowel resection in the rat residual ileum and colon. $J$ Gastroenterol Hepatol. 2003;18: 803-808.

44. Fischer H, Stenling R, Rubio C, Lindblom A. Differential expression of aquaporin 8 in human colonic epithelial cells and colorectal tumors. BMC Physiol. 2001;1:1.

45. Hardin JA, Wallace LE, Wong JF, et al. Aquaporin expression is downregulated in a murine model of colitis and in patients with ulcerative colitis, Crohn's disease and infectious colitis. Cell Tissue Res. 2004;318: 313-323.

46. Zahn A, Moehle C, Langmann T, et al. Aquaporin-8 expression is reduced in ileum and induced in colon of patients with ulcerative colitis. World J Gastroenterol. 2007;13:1687-1695.

47. Wang JP, Hou XH. Expression of aquaporin 8 in colonic epithelium with diarrhoea-predominant irritable bowel syndrome. Chin Med J (Engl) 2007;120:313-316.

48. Zhang W, Xu Y, Chen Z, Xu Z, Xu H. Knockdown of aquaporin 3 is involved in intestinal barrier integrity impairment. FEBS Lett. 2011;585: 3113-3119.

49. Tanaka M, Inase N, Fushimi K, et al. Induction of aquaporin 3 by corticosteroid in a human airway epithelial cell line. Am J Physiol. 1997;273:L1090-L1095.

50. Koyama Y, Yamamoto T, Tani T, et al. Expression and localization of aquaporins in rat gastrointestinal tract. Am J Physiol. 1999;276: C621-C627.

51. McGovern D, Powrie F. The IL23 axis plays a key role in the pathogenesis of IBD. Gut. 2007;56:1333-1336.

52. Sandborn WJ, Hanauer SB. Antitumor necrosis factor therapy for inflammatory bowel disease: a review of agents, pharmacology, clinical results, and safety. Inflamm Bowel Dis. 1999;5:119-133.

53. Olsen T, Goll R, Cui G, et al. Tissue levels of tumor necrosis factor-alpha correlates with grade of inflammation in untreated ulcerative colitis Scand J Gastroenterol. 2007;42:1312-1320. 
54. Dionne S, Hiscott J, D'Agata I, Duhaime A, Seidman EG. Quantitative PCR analysis of TNF-alpha and IL-1 beta mRNA levels in pediatric IBD mucosal biopsies. Dig Dis Sci. 1997;42:1557-1566.

55. Duvallet E, Semerano L, Assier E, Falgarone G, Boissier MC. Interleukin-23: a key cytokine in inflammatory diseases. Ann Med. 2011:43:503-511.

56. Froslie KF, Jahnsen J, Moum BA, Vatn MH. Mucosal healing in inflammatory bowel disease: results from a Norwegian population-based cohort. Gastroenterology. 2007;133:412-422.

57. Fitzgerald PG, Bok D, Horwitz J. Immunocytochemical localization of the main intrinsic polypeptide (MIP) in ultrathin frozen sections of rat lens. J Cell Biol. 1983;97(5 Pt 1):1491-1499.

58. Gorin MB, Yancey SB, Cline J, Revel JP, Horwitz J. The major intrinsic protein (MIP) of the bovine lens fiber membrane: characterization and structure based on cDNA cloning. Cell. 1984;39(1):49-59.

59. Ren G, Reddy VS, Cheng A, Melnyk P, Mitra AK. Visualization of a water-selective pore by electron crystallography in vitreous ice. Proc Natl Acad Sci USA. 2001;98(4):1398-1403.

60. Denker BM, Smith BL, Kuhajda FP, Agre P. Identification, purification, and partial characterization of a novel $\mathrm{Mr} 28,000$ integral membrane protein from erythrocytes and renal tubules. J Biol Chem. 1988;263(30):15634-15642.

61. Fushimi K, Uchida S, Hara Y, Hirata Y, Marumo F, Sasaki S. Cloning and expression of apical membrane water channel of rat kidney collecting tubule. Nature. 1993;361(6412):549-552.

62. Agre P, Sasaki S, Chrispeels MJ. Aquaporins: a family of water channel proteins. Am J Physiol. 1993;265(3 Pt 2):F461.

63. Ishibashi K, Sasaki S, Fushimi K, et al. Molecular cloning and expression of a member of the aquaporin family with permeability to glycerol and urea in addition to water expressed at the basolateral membrane of kidney collecting duct cells. Proc Natl Acad Sci USA. 1994;91(14):6269-6273.

64. Frigeri A, Gropper MA, Turck CW, Verkman AS. Immunolocalization of the mercurial-insensitive water channel and glycerol intrinsic protein in epithelial cell plasma membranes. Proc Natl Acad Sci USA. 1995;92(10):4328-4331.

65. Ho JD, Yeh R, Sandstrom A, et al. Crystal structure of human aquaporin 4 at $1.8 \mathrm{~A}$ and its mechanism of conductance. Proc Natl Acad Sci USA. 2009;106(18):7437-7442.

66. Nielsen S, Nagelhus EA, Amiry-Moghaddam M, Bourque C, Agre P, Ottersen OP. Specialized membrane domains for water transport in glial cells: high-resolution immunogold cytochemistry of aquaporin-4 in rat brain. J Neurosci. 1997;17(1):171-180.

67. Nielsen S, King LS, Christensen BM, Agre P. Aquaporins in complex tissues. II. Subcellular distribution in respiratory and glandular tissues of rat. Am J Physiol. 1997;273(5 Pt 1):C1549-1561.

68. Matsuzaki T, Suzuki T, Koyama H, Tanaka S, Takata K. Aquaporin-5 (AQP5), a water channel protein, in the rat salivary and lacrimal glands: immunolocalization and effect of secretory stimulation. Cell Tissue Res. 1999;295(3):513-521.
69. Ishibashi K, Kuwahara M, GuY, et al. Cloning and functional expression of a new water channel abundantly expressed in the testis permeable to water, glycerol, and urea. J Biol Chem. 1997;272(33):20782-20786.

70. Ishibashi K, Kuwahara M, Kageyama Y, Tohsaka A, Marumo F, Sasaki S. Cloning and functional expression of a second new aquaporin abundantly expressed in testis. Biochem Biophys Res Commun. 1997;237(3):714-718.

71. Tsukaguchi H, Shayakul C, Berger UV, Mackenzie B, Devidas S, Guggino WB, van Hoek AN, Hediger MA. Molecular characterization of a broad selectivity neutral solute channel. J Biol Chem. 1998;273(38):24737-24743.

72. Hatakeyama S, Yoshida Y, Tani T, et al. Cloning of a new aquaporin (AQP10) abundantly expressed in duodenum and jejunum. Biochem Biophys Res Commun. 2001;287(4):814-819.

73. Gorelick DA, Praetorius J, Tsunenari T, Nielsen S, Agre P. Aquaporin-11: a channel protein lacking apparent transport function expressed in brain. BMC Biochem. 2006;7:14.

74. Itoh T, Rai T, Kuwahara M, et al. Identification of a novel aquaporin, AQP12, expressed in pancreatic acinar cells. Biochem Biophys Res Commun. 2005;330(3):832-838.

75. Calamita G, Bishai WR, Preston GM, Guggino WB, Agre P. Molecular cloning and characterization of AqpZ, a water channel from Escherichia coli. J Biol Chem. 1995;270(49):29063-29066.

76. Fu D, Libson A, Miercke LJ, et al. Structure of a glycerolconducting channel and the basis for its selectivity. Science. 2000;290(5491):481-486.

77. Bonhivers M, Carbrey JM, Gould SJ, Agre P. Aquaporins in Saccharomyces. Genetic and functional distinctions between laboratory and wild-type strains. J Biol Chem. 1998;273(42):27565-27572.

78. Laizé V, Gobin R, Rousselet G, et al. Molecular and functional study of AQY1 from Saccharomyces cerevisiae: role of the C-terminal domain. Biochem Biophys Res Commun. 1999;257(1):139-144.

79. Karlgren S, Filipsson C, Mullins JG, Bill RM, Tamás MJ, Hohmann $\mathrm{S}$. Identification of residues controlling transport through the yeast aquaglyceroporin Fps1 using a genetic screen. Eur J Biochem. 2004;271(4):771-779.

80. Dynowski M, Schaaf G, Loque D, Moran O, Ludewig U. Plant plasma membrane water channels conduct the signalling molecule H2O2. Biochem J. 2008;414(1):53-61.

81. Dynowski M, Mayer M, Moran O, Ludewig U. Molecular determinants of ammonia and urea conductance in plant aquaporin homologs. FEBS Lett. 2008;582(16):2458-2462.

82. Nielsen S, DiGiovanni SR, Christensen EI, Knepper MA, Harris HW. Cellular and subcellular immunolocalization of vasopressin-regulated water channel in rat kidney. Proc Natl Acad Sci USA. 1993:90(24);11663-11667. 


\section{Supplementary material}

Table SI TaqMan gene expression assays employed to monitor aquaporin expression

\begin{tabular}{|c|c|c|c|c|c|c|}
\hline $\begin{array}{l}\text { Gene } \\
\text { product }\end{array}$ & Substrate & $A B I$ assay ID ${ }^{a}$ & $\begin{array}{l}\text { Interrogated } \\
\text { sequence RefSeq }\end{array}$ & $\begin{array}{l}\text { Translated } \\
\text { protein RefSeq }\end{array}$ & NCBI location chromosome & Exon boundary \\
\hline$\overline{A Q P I}$ & $\mathrm{H}_{2} \mathrm{O}$ & Hs00166067_ml b & NM_198098.I & NP_932766.I & Chr. $7-3095|4| 5-30965|3|$ & I-2, assay loc: 492 \\
\hline AQP3 & $\begin{array}{l}\mathrm{H}_{2} \mathrm{O} \\
\text { Glycerol } \\
\mathrm{H}_{2} \mathrm{O}_{2} \\
\mathrm{NH}_{4}^{+} \\
\text {Urea }\end{array}$ & Hs00I85020_ml & NM_004925.3 & NP_004916.I & Chr. 9 - 3344II 58-33447590 & $2-3$ assay loc: 297 \\
\hline AQP4 & $\mathrm{H}_{2} \mathrm{O}$ & Hs00242342_ml & NM_00I650.4 & NP_00I64I.I & Chr. 18 - 24432007-244457/6 & $2-3$ assay loc: 508 \\
\hline AQP5 & $\mathrm{H}_{2} \mathrm{O}$ & $\mathrm{Hs} 00387048 \_\mathrm{ml}$ & NM_00I65I.2 & NP_00I642.I & Chr. I2-50355279-5035946I & I-2 assay loc: 888 \\
\hline AQP7 & $\begin{array}{l}\mathrm{H}_{2} \mathrm{O} \\
\text { Glycerol } \\
\text { Urea }\end{array}$ & Hs00357359_ml & NM_00II70.I & NP_00II6I.I & Chr. 9 - 33384948-334025I7 & 2-3 assay loc: 199 \\
\hline AQP8 & $\begin{array}{l}\mathrm{H}_{2} \mathrm{O} \\
\mathrm{H}_{2} \mathrm{O}_{2} \\
\mathrm{NH}_{4}^{+}\end{array}$ & $\mathrm{Hs} 00 \mathrm{I} 54 \mathrm{I} 24 \_\mathrm{ml}$ & NM_00II69.2 & NP_00II 60.2 & Chr. $16-25228285-25240253$ & 2-3 assay loc: 339 \\
\hline AQP9 & $\begin{array}{l}\mathrm{H}_{2} \mathrm{O} \\
\text { Glycerol } \\
\text { Urea }\end{array}$ & Hs00I75573_ml & NM_020980.3 & NP_066190.2 & Chr. I5 - 58430408-58478I I0 & I-2 assay loc: 467 \\
\hline TNF- $\alpha$ & & Hs99999043_ml & NM_000594.2 & NP_000585.2 & Chr. 6-3I543350-31546II2 & I-2 assay loc: 360 \\
\hline IL-23A & & Hs00372324_ml & NM_0I6584.2 & NP_057668.I & Chr. $12-56732663-56734194$ & I-2 assay loc: 323 \\
\hline $\begin{array}{l}\text { COX-2/ } \\
\text { PTGS2 }\end{array}$ & & Hs00I53I33_ml & NM_000963.2 & NP_000954.I & Chr. I - I86640944-I86649559 & 5-6 assay loc: 777 \\
\hline
\end{tabular}

Notes: aAll assays used dye label FAM; ' ${ }^{\text {An }}$ assay whose probe spans an exon junction and does not detect genomic DNA.

Abbreviations: HS, Homo sapiens; AQP, aquaporin; IL, interleukin; loc, location; COX-2, cyclooxygenase 2; TNF- $\alpha$, tumor necrosis factor- $\alpha$.

Table S2 Comparison of aquaporin mRNA levels in the small and large bowel biopsies from CD and UC patients and non-IBD patient controls

\begin{tabular}{|c|c|c|c|c|c|c|c|c|c|}
\hline & \multicolumn{3}{|c|}{ lleum vs right colon } & \multicolumn{3}{|c|}{ Ileum vs left colon } & \multicolumn{3}{|c|}{ Right vs left colon } \\
\hline & mRNA ratio & $P$-value & $q$-value & mRNA ratio & $P$-value & q-value & mRNA ratio & $P$-value & q-value \\
\hline \multicolumn{10}{|l|}{$C D$} \\
\hline AQP4 & $\mathrm{Neg}^{\mathrm{a}}$ & $\mathrm{Neg}$ & Neg & Neg & Neg & Neg & Neg & Neg & Neg \\
\hline AQP5 & $\mathrm{Neg}$ & $\mathrm{Neg}$ & Neg & $\mathrm{Neg}$ & Neg & Neg & Neg & Neg & Neg \\
\hline AQP9 & 1.77 & 0.07 & 0.12 & 1.16 & 0.54 & 0.62 & 0.65 & 0.89 & 1.0 \\
\hline \multicolumn{10}{|l|}{ UC } \\
\hline AQP4 & Neg & Neg & Neg & Neg & Neg & Neg & Neg & Neg & Neg \\
\hline AQP5 & Neg & Neg & $\mathrm{Neg}$ & 0.22 & 0.41 & 0.46 & 1.13 & 0.55 & 0.68 \\
\hline AQP9 & 0.33 & 0.04 & 0.07 & 0.31 & 0.12 & 0.19 & 0.95 & 0.68 & 0.7 \\
\hline \multicolumn{10}{|l|}{ Controls } \\
\hline AQP4 & Neg & Neg & Neg & Neg & Neg & Neg & Neg & Neg & Neg \\
\hline AQP5 & 5.0 & 0.35 & 0.52 & Neg & Neg & Neg & Neg & Neg & Neg \\
\hline AQP9 & 0.55 & 0.66 & 0.66 & 0.21 & 0.51 & 0.75 & Neg & $\mathrm{Neg}$ & Neg \\
\hline
\end{tabular}

Notes: mRNA levels detected by qRT-PCR are given as mRNA ratios calculated from delta delta $C_{T}$ values with $P$-values and multiple testing adjusted $P$-values ( $q$-values). ${ }^{a} \mathrm{Neg}=$ negative/below detection level (very low levels or no mRNA detected/the concentration of corresponding mRNAs was below the threshold for detection by qRTPCR).

Abbreviations: AQP, aquaporin; CD, Crohn's disease; COX-2, cyclooxygenase 2; IBD, inflammatory bowel disease; mRNA, messenger RNA; qRT-PCR, quantitative realtime polymerase chain reaction; UC, ulcerative colitis; vs, versus. 
Table S3 Comparison of aquaporin mRNA levels from CD and UC patients and non-IBD patient controls in the small and large bowel biopsies

\begin{tabular}{|c|c|c|c|c|c|c|c|c|c|}
\hline & \multicolumn{3}{|c|}{ CD vs controls } & \multicolumn{3}{|l|}{$C D$ vs UC } & \multicolumn{3}{|c|}{ UC vs controls } \\
\hline & mRNA ratio & $P$-value & q-value & mRNA ratio & $P$-value & q-value & mRNA ratio & $P$-value & q-value \\
\hline \multicolumn{10}{|l|}{ Ileum } \\
\hline AQPI & 0.54 & 0.07 & 0.13 & 0.43 & $<0.001$ & 0.002 & 1.28 & 0.37 & 0.61 \\
\hline AQP3 & 0.15 & $<0.001$ & 0.003 & 0.16 & $<0.001$ & $<0.001$ & 0.94 & 0.87 & 0.87 \\
\hline AQP7 & 1.16 & 0.67 & 0.67 & 4.31 & 0.002 & 0.006 & 0.27 & 0.003 & 0.02 \\
\hline AQP8 & 7.33 & 0.29 & 0.36 & 260.96 & 0.005 & 0.01 & 0.03 & 0.07 & 0.17 \\
\hline COX-2 & 2.56 & 0.075 & 0.13 & 0.57 & 0.31 & 0.38 & 4.51 & 0.014 & 0.05 \\
\hline TNF- $\alpha$ & 2.94 & 0.06 & 0.13 & 4.00 & 0.01 & 0.02 & 0.73 & 0.62 & 0.69 \\
\hline IL-23A & 4.43 & 0.03 & 0.10 & 6.93 & 0.01 & 0.017 & 0.64 & 0.56 & 0.69 \\
\hline \multicolumn{10}{|l|}{ Right colon } \\
\hline AQPI & 0.83 & 0.72 & 0.72 & 0.90 & 0.98 & 0.98 & 0.84 & 0.78 & 0.78 \\
\hline AQP3 & 0.82 & 0.63 & 0.72 & 1.26 & 0.53 & 0.77 & 0.65 & 0.40 & 0.45 \\
\hline AQP7 & 1.97 & 0.37 & 0.59 & 10.98 & $<0.001$ & 0.001 & 0.18 & 0.06 & 0.17 \\
\hline AQP8 & 0.25 & 0.03 & 0.27 & 52.46 & 0.008 & 0.04 & 0.01 & 0.001 & 0.009 \\
\hline $\operatorname{cox}-2$ & 1.41 & 0.21 & 0.51 & 0.32 & 0.02 & 0.051 & 4.35 & 0.003 & 0.02 \\
\hline TNF- $\alpha$ & 0.76 & 0.68 & 0.72 & 2.06 & 0.07 & 0.12 & 0.37 & 0.17 & 0.31 \\
\hline IL-23A & 2.57 & 0.21 & 0.51 & 1.17 & 0.77 & 0.87 & 2.19 & 0.27 & 0.35 \\
\hline \multicolumn{10}{|l|}{ Left colon } \\
\hline AQPI & 0.87 & 0.77 & 0.86 & 1.06 & 0.84 & 0.84 & 0.82 & 0.67 & 0.77 \\
\hline AQP3 & 0.54 & 0.09 & 0.34 & 0.78 & 0.31 & 0.40 & 0.70 & 0.30 & 0.40 \\
\hline AQP7 & 1.09 & 0.86 & 0.86 & 11.65 & $<0.001$ & $<0.001$ & 0.09 & $<0.001$ & $<0.001$ \\
\hline AQP8 & 0.08 & 0.004 & 0.03 & 247.47 & $<0.001$ & 0.002 & 0.0003 & $<0.001$ & $<0.001$ \\
\hline cox-2 & 1.60 & 0.37 & 0.49 & 0.16 & 0.003 & 0.007 & 9.81 & $<0.001$ & $<0.001$ \\
\hline TNF- $\alpha$ & 2.08 & 0.26 & 0.42 & 2.17 & 0.03 & 0.06 & 0.96 & 0.95 & 0.95 \\
\hline IL-23A & 2.66 & 0.13 & 0.43 & 0.79 & 0.58 & 0.65 & 3.36 & 0.06 & 0.12 \\
\hline
\end{tabular}

Note: mRNA levels detected by $q R T$-PCR are given as mRNA ratios calculated from delta delta $C_{T}$ values with $P$-values and multiple testing adjusted $P$-values ( $q$-values). Abbreviations: AQP, aquaporin; CD, Crohn's disease; COX-2, cyclooxygenase 2, IBD, inflammatory bowel disease; IL, interleukin; mRNA, messenger RNA; qRT-PCR, quantitative real-time polymerase chain reaction; TNF- $\alpha$, tumor necrosis factor- $\alpha$; UC, ulcerative colitis; vs, versus. 


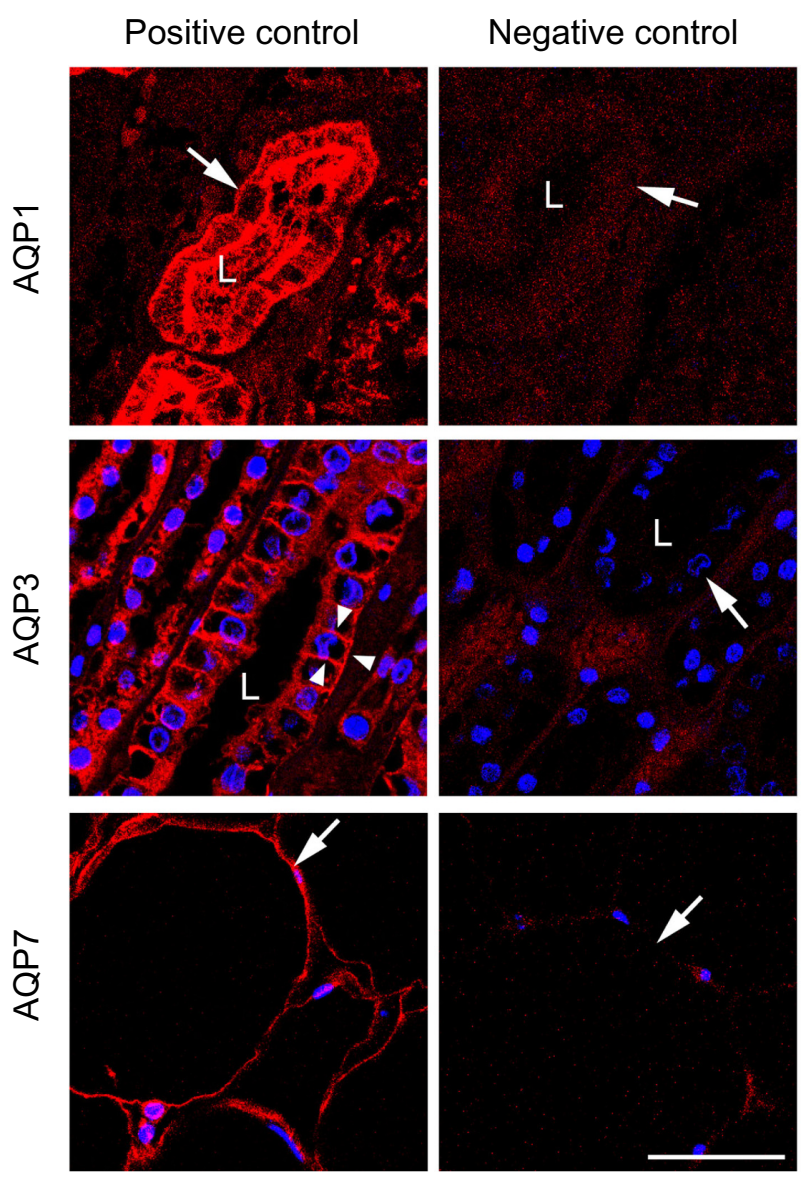

Figure SI AQP expression in healthy human tissues.

Notes: The left panel (positive controls) shows micrographs with immunofluorescence labeling of human samples with AQPI, AQP3, and AQP7 antibodies. The tubular lumina are marked $\mathrm{L}$. AQPI is localized at the brush border and basolateral membranes of the renal proximal tubule (arrow, upper panel), AQP3 is localized at the basolateral membranes of the collecting ducts (arrowheads, middle panel) and AQP7 is localized at the plasma membrane of dipocytes (arrow, lower panel). The right panel (negative controls) shows sections from the same tissue as in the left panel, treated the same way, in absence of the primary antibody. No labeling is observed, excluding nonspecific labeling with the secondary antibodies. Scale bar: $50 \mu \mathrm{m}$.

Abbreviation: $\mathrm{AQP}$, aquaporin.

\section{Publish your work in this journal}

Clinical and Experimental Gastroenterology is an international, peerreviewed, open access journal, publishing all aspects of gastroenterology in the clinic and laboratory, including: Pathology, pathophysiology of gastrointestinal disease; Investigation and treatment of gastointes tinal disease; Pharmacology of drugs used in the alimentary tract;
Immunology/genetics/genomics related to gastrointestinal disease. This journal is indexed on CAS. The manuscript management system is completely online and includes a very quick and fair peer-review system. Visit http://www.dovepress.com/testimonials.php to read real quotes from published authors. 